\title{
Development
}

\section{Myosin Va Brain-Specific Mutation Alters Mouse Behavior and Disrupts Hippocampal Synapses}

\author{
Swarna Pandian, ${ }^{1,3,4}$ Jian-Ping Zhao, ${ }^{1}$ - Yasunobu Murata, ${ }^{1}$-Fernando J. Bustos, ${ }^{1,2}$ Cansu Tunca, ${ }^{1}$ \\ (-)Ramiro D. Almeida, ${ }^{3}$ and Martha Constantine-Paton ${ }^{1}$
}

\section{https://doi.org/10.1523/ENEURO.0284-20.2020}

${ }^{1}$ Department of Brain and Cognitive Sciences, McGovern Institute for Brain Research, Massachusetts Institute of Technology, Cambridge, MA 02139, ${ }^{2}$ Institute of Biomedical Sciences, Faculty of Medicine and Faculty of Life Sciences, Universidad Andres Bello, Santiago, Chile 8370071, ${ }^{3}$ Centre for Neuroscience and Cell Biology, University of Coimbra, Coimbra 3004-517, Portugal, and ${ }^{4}$ Instituto Superior Técnico Av. Rovisco Pais 1, 1049-001 Lisboa, Portugal

\begin{abstract}
Myosin Va (MyoVa) is a plus-end filamentous-actin motor protein that is highly and broadly expressed in the vertebrate body, including in the nervous system. In excitatory neurons, MyoVa transports cargo toward the tip of the dendritic spine, where the postsynaptic density (PSD) is formed and maintained. MyoVa mutations in humans cause neurologic dysfunction, intellectual disability, hypomelanation, and death in infancy or childhood. Here, we characterize the Flailer (Flr) mutant mouse, which is homozygous for a myo5a mutation that drives high levels of mutant MyoVa (FIr protein) specifically in the CNS. FIr protein functions as a dominantnegative MyoVa, sequestering cargo and blocking its transport to the PSD. Flr mice have early seizures and mild ataxia but mature and breed normally. Flr mice display several abnormal behaviors known to be associated with brain regions that show high expression of Flr protein. FIr mice are defective in the transport of synaptic components to the PSD and in mGluR-dependent long-term depression (LTD) and have a reduced number of mature dendritic spines. The synaptic and behavioral abnormalities of Flr mice result in anxiety and memory deficits similar to that of other mouse mutants with obsessive-compulsive disorder and autism spectrum disorder (ASD). Because of the dominant-negative nature of the FIr protein, the Flr mouse offers a powerful system for the analysis of how the disruption of synaptic transport and lack of LTD can alter synaptic function, development and wiring of the brain and result in symptoms that characterize many neuropsychiatric disorders.
\end{abstract}

Key words: anxiety; autism spectrum disorder; LTD; transport

\section{Significance Statement}

Here, we characterize a mutant mouse homozygous for a Myosin Va (MyoVa) mutation named Flailer (Flr). The FIr mutation generates a dominant-negative MyoVa transport motor protein that sequesters synaptic cargo and blocks synaptic transport, thereby resulting in an absence of long-term depression (LTD) and in abnormal behaviors similar to those seen in anxiety and autism spectrum disorders (ASDs). We propose that the FIr mutant can be used as a model to study how the absence of LTD disrupts brain connectivity and behavior. Moreover, by using the FIr mutation together with gene editing technologies it should be possible to target specific brain areas to remove the mutation and recover MyoVa function, thereby interrogating the role of a specific brain region in the control of a particular behavior.

Received June 27, 2020; accepted October 7, 2020; First published November 23, 2020.

The authors declare no competing financial interests.
Author contributions: S.P., R.D.A., and M.C.-P. designed research; S.P., J.-P.Z., Y.M., and C.T. performed research; S.P., Y.M., F.J.B., and M.C.-P. analyzed data; S.P., F.J.B., and M.C.-P. wrote the paper. 


\section{Introduction}

Myosin Va (MyoVa) is a plus-end filamentous-actin motor protein that is highly expressed throughout the vertebrate body, including in the nervous system (Mercer et al., 1991; Hammer and Sellers, 2011). Mutant MyoVa in humans produces an early lethal disease called Elejalde or Griscelli syndrome Type I, which is characterized by abnormal pigmentation and severe neurologic symptoms (Griscelli et al., 1978; Elejalde et al., 1979; Pastural et al., 1997; Durán-McKinster et al., 1999; Sanal et al., 2000). Similar to humans with Griscelli syndrome, MyoVa null mice (dilute-lethal) die early, either in utero or before postnatal day (P)21. However, rodent strains with small spontaneous myo5a mutations display milder phenotypes and have made possible studies of abnormal cerebellar function (Takagishi and Murata, 2006; Miyata et al., 2011).

The Flailer (Flr) mouse is homozygous for a myo5a mutation caused by a spontaneous non-homologous recombination event that produced a fusion gene lacking the coding region for the actin-binding "feet" of the MyoVa protein. The actin-binding domains are critical, since they allow Myova to "walk" toward the positive end of, and move between, actin filaments (Hammer and Sellers, 2011; Wagner et al., 2011). In the Flr mutant, this myoVa gene is fused to the promoter of the gene guanine nucleotide-binding protein subunit $\beta-5$ (gnb5) and as a consequence is expressed extensively in the CNS (Watson et al., 1994; Zhang et al., 2000, 2011; Witherow and Slepak, 2003; Lein et al., 2007; Allen Brain Atlas). When the Flr mutant protein is in a 1:1 ratio with wild-type (WT) myo5a protein, the Flr protein competes with WT MyoVa for cargo by forming abnormal myosin dimers that sequester cargo but are unable to step toward the postsynaptic density (PSD) on actin, thereby diminishing MyoVa function. In the WT brain, MyoVa carries many critical molecules and complexes along actin filaments in dendritic spine necks to distal spine synapses (Jones et al., 2000; Hammer and Sellers, 2011), including vesicle-bound

This work was supported by National Institutes of Health Grants R01EY014074 and R01-EY014420 (to M.C.P.). S.P. was supported by the MITPortugal Program, the Portuguese Foundation for Science and Technology Grant SFRH/BD/33726/2009 as a graduate student, and by the McGovern Institute for Brain Research as a postdoctoral fellow. F.J.B. was a Simons Center for the Social Brain Postdoctoral Fellow at MIT and a Pew Latin American Postdoctoral Fellow and is funded by the FONDECYT (Fondo Nacional de Desarrollo Científico y Tecnológico) 11180540. ANID (Agencia Nacional de Investigación y Desarrollo de Chile) PAI 77180077.

Acknowledgements: We thank Prof. H. Robert Horvitz and Prof. Joe Paton for reading this manuscript and helpful feedback. We also thank Prof. Glen Prusky and Nazia Alam, Weill Cornell Medical College, for helping us with the visual acuity test; Stanley Center, Prof. Mriganka Sur's Lab, and Prof. Gouping Feng's Lab for behavioral equipment; and Prof. Tomaso Poggio and Nicholas Edelman for development and setting up of the automated phenotyping system for mouse grooming behavior.

Correspondence should be addressed to Fernando J. Bustos at fernando. bustos@unab.cl.

https://doi.org/10.1523/ENEURO.0284-20.2020

Copyright (C) 2020 Pandian et al.

This is an open-access article distributed under the terms of the Creative Commons Attribution 4.0 International license, which permits unrestricted use, distribution and reproduction in any medium provided that the original work is properly attributed. molecules such as receptors, mRNAs translated at the synapse (Fujii et al., 2005; Yoshimura et al., 2006), and synaptic scaffolding complexes (Gerrow et al., 2006; Moutin et al., 2012; Yoshii et al., 2013). These scaffolding complexes are necessary to localize receptors and organize other molecules at the relatively isolated spine tip PSDs. Interestingly, the Flr phenotype is expressed only when the flr mutant gene is present in at least as many copies as the WT myo5a gene. More specifically, the Flr phenotype requires two copies of the flr mutant gene (hence appears to be recessive, although there is no second "WT" allele of the flr gene) in a WT myo5a background with two WT myo5a alleles, but requires only one copy (hence appears to be dominant) in a myo5a heterozygote with one myo5a null allele and one WT myo5a allele. These observations suggest that the flr mutation acts as a myo5a dominant-negative mutation (Jones et al., 2000).

Researchers studying MyoVa function have designed similar truncated constructs and over-expressed them in a variety of cells in vitro in attempts to block WT MyoVa function; however the high and scattered expression levels make the interpretation of these data difficult (Correia et al., 2008). Conversely, Flr animals show intact cellular function and behavior that is essentially the same in every animal and thus provide an excellent model organism for the study of MyoVa function in the brain.

Previously we characterized some of the synaptic defects of the Flr mouse visual cortex (VC), where we found long-term potentiation (LTP) to be normal but no evidence of long-term depression (LTD; Yoshii et al., 2013). Moreover, AMPA receptor (AMPAR) endocytosis was defective, AMPAR miniature current frequencies were significantly increased, and AMPAR to NMDA receptor (NMDAR)-evoked current ratios were abnormally high in VC neurons as recorded in brain slices. Also, immunocytochemical studies of cultured VC pyramidal cells showed generally increased expression of AMPARs, which in FIr mice are located in dendritic shafts rather than in spines because of the diminished transport by Myova (Yoshii et al., 2013).

Here, we characterize the Flr animal using behavioral testing, biochemistry and electrophysiology. These animals show repetitive grooming, anxiety, asocial behaviors, defective hippocampal memory, and abnormal pup vocalizations. The behaviors suggest that the FIr protein disruption of glutamate synapses produces an anxiety, obsessive compulsive-like phenotype similar to those seen in mouse strains in which neuropsychiatric candidate genes have been mutated (Welch et al., 2007; McFarlane et al., 2008; Peñagarikano et al., 2011; Peça and Feng, 2012). In addition, we observed a severe deficit in the transport of synaptic components to the synapse and a lack of LTD in the hippocampus of Flr animals. Our study highlights the important role for LTD in the etiology of mouse and presumably human, autism spectrum disorder (ASD)-related syndromes and, if combined with gene editing technologies, offers a new experimental approach to identifying the brain circuits responsible for neuropsychiatric disorders. 


\section{Material and Methods}

\section{Animals}

All animal manipulations were performed following the guidelines of the Massachusetts Institute of Technology Institutional Animal Care and Use Committee (IACUC). FIr mice, line B6CBACa-A ${ }^{W J} / A, t b^{2 J} / t b^{2 J} F_{2}$ from the frozen embryo repository at Jackson Laboratory (Bar Harbor, $\mathrm{ME}$ ), were bred as described in Jones et al. (2000) and supplied to us as pairs from their BcC-flr congenic line by the laboratory of Professor Miriam Meisler, University of Michigan, Ann Arbor, MI. Animals were rederived and maintained in the MIT IACUC. BcC-flr mice used for the current experiments were crossed with Thy-1 EGFP mice (Feng et al., 2000) to obtain F1 heterozygotes and subsequently bred to homozygosity for the flr gene. $\mathrm{WT}_{\mathrm{FLR}}$-GFP animals were also obtained from these crosses. Both strains were bred for a subsequent fouryears in our laboratory. Genotypes were determined by PCR from mouse ear clippings (http:// www.transnetyx.com/Services/Automated Genotyping. aspx). Animals were maintained at $23^{\circ} \mathrm{C}$ in the MIT IACUC facility with a 12/12 h light/dark cycle and food and water available ad libitum.

\section{Quantitative Western blotting}

Synaptosomes were prepared as previously reported in (Yoshii et al., 2013). Briefly, hippocampal tissues were collected from P25 to P29 WT or Flr animals of both sexes in ice-cold TEVP buffer containing the following: $10 \mathrm{~mm}$ Tris- $\mathrm{HCl}, 5 \mathrm{~mm} \mathrm{NaF}, 1 \mathrm{~mm} \mathrm{Na} \mathrm{VO}_{4}, 1 \mathrm{~mm}$ EDTA, $1 \mathrm{~mm}$ EGTA, pH 7.4, and 320 mm sucrose. Samples were homogenized using a tissue grinder and centrifuged at $1000 \times g$ to remove nuclei and large debris. Supernatants were centrifuged at $10,000 \times g$ and the pellet was resuspended in TEVP buffer. Pellets were centrifuged at $25,000 \times g$ to collect the synaptosomal membrane fraction. After each centrifugation pellets was rinsed with ice-cold TEVP buffer to reduce contamination among fractions. Concentrations were determined with BCA assays (Pierce). Proteins were electrophoretically separated on 4-12\% SDS-PAGE gels and transferred to a PVDF membrane (Millipore). Membranes were subsequently blocked with blocking buffer (Sigma) and then incubated with primary antibodies overnight at $4{ }^{\circ} \mathrm{C}$, rinsed, and then incubated with secondary antibodies for $30 \mathrm{~min}$ at room temperature (RT). Primary antibodies used were: rabbit anti-MyoVa (Sigma, LE18), mouse anti-TLS (Santa Cruz, sc-47711), rabbit antimGluR1 (Millipore, 07-617), rabbit anti-mGluR5 (Neuromics, RA16100), mouse anti-fragile $X$ mental retardation protein (FMRP; Millipore, 1C3), mouse anti-PSD-95 (NeuroMab, K28/43), mouse anti-PSD-93 (NeuroMab, N18/30), mouse anti-SAP102 (NeuroMab, N19/2), mouse anti-SAPAP1 (NeuroMab, N238/29), mouse anti-Shank1 (NeuroMab, N22/21), mouse anti-Shank3 (NeuroMab, N367/ 62), mouse anti-GluN1 (NeuroMab, N308-48), rabbit antiGluN2A (Millipore, A12W), mouse anti-GluN2B (NeuroMab N59/20 and N59/36), mouse anti-GluA2 (NeuroMab, L21/ 32), mouse anti-homer 1 (NeuroMab, L113/130), mouse antiIP3R (NeuroMab, N18/30), rabbit anti-tubulin $\beta$ III (Abcam, ab6046), and mouse anti-actin (Sigma, AC-74). Blots were developed using chemiluminescence (Pierce. IL). Tubulin$\beta$ III or $\beta$-actin bands on the same blot were used as loading controls. Band intensities, were confirmed to be in the linear range and then quantified using ImageJ software. At least three separate protein samples were used for quantification.

\section{In vitro electrophysiology}

Acute slices were prepared from either Flr or $\mathrm{WT}_{\mathrm{FLR}}$. Animals were anesthetized with isoflurane and decapitated. Brains were quickly removed and chilled in ice-cold dissection buffer. Transverse dorsal hippocampal 350- to $400-\mu \mathrm{m}$ sections were cut using a VT-1000S vibratome (Leica) in ice-cold carbogenated sucrose solution containing the following: $240 \mathrm{~mm}$ sucrose, $2.5 \mathrm{~mm} \mathrm{KCl,} 1 \mathrm{~mm}$ $\mathrm{CaCl}_{2}, 5 \mathrm{~mm} \mathrm{MgSO}_{4}, 26 \mathrm{~mm} \mathrm{Na}_{2} \mathrm{HCO}_{3}, 1 \mathrm{~mm} \mathrm{NaH} \mathrm{PO}_{3}$, and $11 \mathrm{~mm}$ glucose, transferred to a chamber containing aerated artificial CSF (ACSF) for $30 \mathrm{~min}$ at $32^{\circ} \mathrm{C}$ then maintained at RT $\left(22-24^{\circ} \mathrm{C}\right)$ for a minimum of $1 \mathrm{~h}$ before electrophysiology recordings. Electrodes from borosilicate glass (WPI Sarasota) were pulled to 1- to 3-M $\Omega$ tip resistance using a P-97 puller (Sutter Instruments). For recordings, slices were submerged and perfused $(3 \mathrm{ml} / \mathrm{min})$ in a carbogen-saturated ACSF solution at RT. Stimulating electrodes were fabricated from tungsten bipolar electrodes (WPI) driven by ISO-STIM-01D (NPI Electronic GmbH). Field potentials were recorded in stratum radiatum of $\mathrm{CA} 1$, amplified with a MultiClamp 700B Axopatch 200B, digitized with a Digidata $1440 \mathrm{~A}$, filtered at $2 \mathrm{kHz}$, sampled at $10 \mathrm{kHz}$ and stored in a computer that provided both on-line display and off-line data analysis using pClamp 10.2 and Clampfit 10.2 software (Mol. Devices Corp.).

\section{Dendritic protrusion density analysis}

Male WT and FIr GFP mice were anesthetized with isoflurane and transcardially perfused with PBS followed by $4 \%$ paraformaldehyde (PFA) in PBS. Brains were dissected and postfixed with $4 \%$ PFA at $4{ }^{\circ} \mathrm{C}$ for at least $12 \mathrm{~h}$. The hippocampus was removed for transverse sectioning. Images were obtained with a confocal microscope (Nikon PCM2000 MVI) using a $60 \times$ oil-immersion objective with $2 \times$ magnification. Multiple $0.5-\mu \mathrm{m}$ optical sections were used to analyze dendritic protrusions using Neurolucida Software (MBF Bioscience).

\section{Behavior analysis}

Adult male mice were used for all behavior analyses except for pup vocalizations. All observers were blind to the phenotype of the mouse unless otherwise stated.

\section{Grooming behaviors}

After 10 min of habituation to a fresh cage, mice were videotaped for $24 \mathrm{~h}$ under 700 lux day lighting (12 h) and $\sim 2$ lux red light at night (12 h) illuminations. Grooming behaviors recorded at the onset of dark cycle (7-8 P.M.) were studied using an automated home-cage behavioral phenotyping system (Jhuang et al., 2010) designed by the Poggio laboratory in the McGovern Institute with manual 
corrections. The videos shown were taken in Plexiglas cubicles to illustrate details in Flr grooming.

\section{Elevated plus maze}

We used a standard elevated plus maze as described previously (Munekazu et al., 2008). Each test session lasted 5 min. Scoring was accomplished using Ethovision XT Noldus Observer software.

\section{Three-chamber social approach test}

The three-chamber test for sociability was performed as previously described (Moy et al., 2004) with minor modifications. A WT $\mathrm{FLR}_{\mathrm{R}}$ mouse was placed in the central chamber separated by opaque panels with holes providing passage between chambers. A novel male mouse was held in a wired cage allowing visual, tactile, and olfactory contact. Video recordings of the introduced mouse were taken for the following 10-min period.

\section{Social proximity tests}

Social proximity testing was conducted in a clear rectangular chamber constructed of acrylic plastic under dim red light as previously described (Defensor et al., 2011). For testing, two non-cage male mice were simultaneously placed in the testing chamber for a $10 \mathrm{~min}$ trial. Either two mice of the same strain or one Flr and one $\mathrm{WT}_{\mathrm{FLR}}$ were placed in the chamber. The entire test period was videotaped from two cameras providing front and side views. All behaviors involved some contact between the two animals.

\section{Morris water maze}

Before the spatial memory trials, mice were taught the location of a transparent lucite platform $(10 \times$ $10 \mathrm{~cm}$ ) submerged just underneath the surface of the water. Two sets of trials were performed from four independent drop location (East, West, South, and North of the platform) on training day. Memory for the platform location was assessed during four consecutive spatial trials $24 \mathrm{~h}$ later. For all spatial trials, swim distance (meters) and swim speed (meters per second) were recorded.

\section{Fear conditioning}

Standard fear conditioning paradigms were used to test for freezing to context in standard fear-conditioning chambers housed in sound-attenuating boxes (MED Associates, St. Albans, VT). Twenty-four hours after a 5 -min placement in the chamber with a 180-s noise (85$\mathrm{dB})$ stimulus followed immediately by a $2-\mathrm{s}(0.6-\mathrm{mA})$ mild shock, mice were placed back into the same chambers. Freezing to the context provided by the box alone was assessed over $5 \mathrm{~min}$. Cued stimulus fear conditioning was evaluated $2 \mathrm{~h}$ later in altered chambers. Freezing in the absence of the cued stimulus was assessed during the first $180 \mathrm{~s}$ of the test session, then the noise $(85 \mathrm{~dB})$ was presented and freezing to this cued stimulus was assessed.

\section{Communication deficits}

Pups (P2-P14) were isolated from their mother and littermates for $10 \mathrm{~min}$. For testing, pups were gently placed into a glass isolation container containing clean bedding material and surrounded by a sound attenuating box $(18 \times 18 \times 18 \mathrm{~cm})$ made of 4 -mm-thick Styrofoam. An ultrasound Gate system monitored ultrasonic vocalization (USV) emission. Acoustic data were recorded with a sampling rate of $250,000 \mathrm{~Hz}$ in 16-bit format by a recorder (version 2.97; Avisoft Bioacoustics). For acoustical analysis, recordings were transferred to Avisoft SASLab Pro (version 4.50; Avisoft Bioacoustics)

\section{Data analysis}

Statistical analyses were performed using GraphPad Prism software. $t$ test paired, unpaired $t$ test or ANOVA tests were performed as described in each figure; ${ }^{*} p \leq 0.05,{ }^{* *} p \leq 0.001,{ }^{* * *} p \leq 0.0001$.

\section{Results}

\section{FIr animals show anxiety, memory defects, and} deficits in social interactions

The flr gene consists of the promoter and first two exons of brain-specific gnb5 plus part of the adjacent intron fused in-frame with an intron of myo5a, allowing the gnb5 promoter to drive the expression of truncated myo5a and express the FIr protein (Jones et al., 2000) at levels equal to WT MyoVa in the many brain regions in which Gnb5 is expressed (Zhang et al., 2000). Gnb5 forms complexes with members of the regulators of Gprotein signaling (RGS) family to control G-proteins, including mGluR6 (Rao et al., 2007). In response to light and photoreceptor glutamate release, mGluR6 activation closes a non-selective cation channel in ON-retinal bipolar cell dendrites (Morgans et al., 2007). This closure depolarizes the otherwise hyperpolarized cells.

Because abnormal expression of the Flr protein in retinal bipolar cells might seriously compromise vision, we first tested the grating acuity of four mature (P56-P84) Flr and four age-matched WT mice with the Flr genetic background, hereafter referred to as $\mathrm{WT}_{\mathrm{FLR}}$. We used scoptopic conditions, the virtual oculomotor system designed and constructed by Prusky et al. (2004). $\mathrm{WT}_{\mathrm{FLR}}$ animals showed average grating acuities in their right and left eyes of 0.388 and 0.389 cycles per degree (cyc/deg), respectively, while the Flr mice showed a somewhat lower acuity of $0.345 \mathrm{cyc} / \mathrm{deg}$ for both eyes, indicating that despite a slightly lower acuity the FIr mutants were sufficiently visual to detect their environments and have reasonably normal environmental stimulation of their central nervous systems.

Next, using adult (P56-P84) male Flr and WT mice, we characterized the behaviors displayed by the animals. In all cases both training and testing took place within the first $3 \mathrm{~h}$ of the dark cycle. All behavioral tests were conducted using male animals, hence, our data are only valid for males. To determine the anxiety levels shown by Flr animals, we performed three tests. The most salient 
A

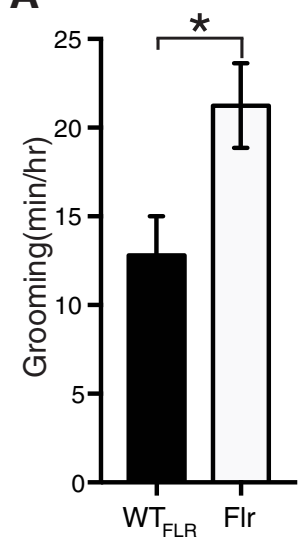

D

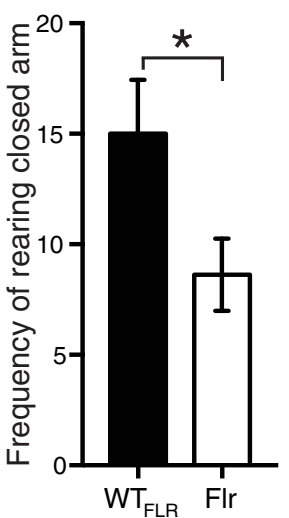

B

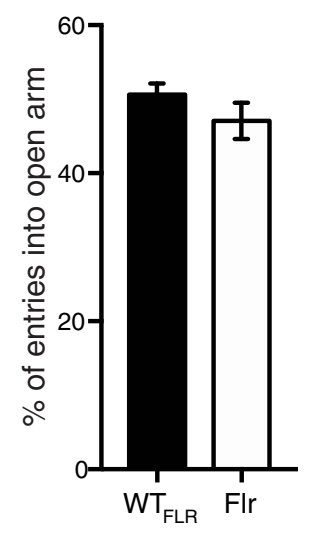

E

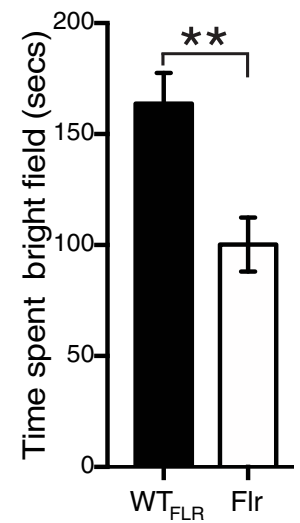

C

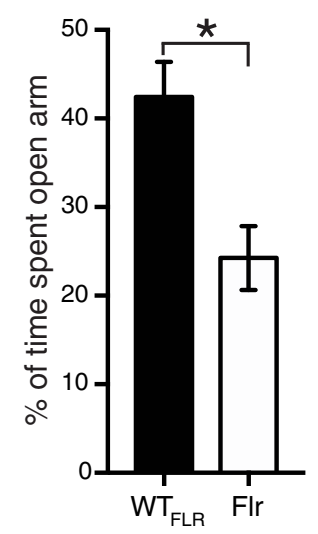

$\mathbf{F}$

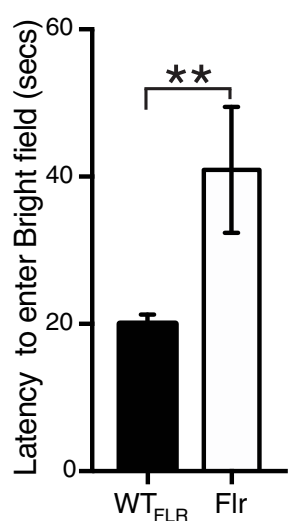

Figure 1. Flr mice show anxiety-like behaviors. $\boldsymbol{A}$, Quantification of the time spent grooming $\left(n=6\right.$ for both Flr and $\mathrm{WT}_{\mathrm{FLR}}$; Movies 1, 2). $\boldsymbol{B}-\boldsymbol{D}$, Elevated plus maze to test entries into the open arms $(\boldsymbol{B})$, time spent in the open arms compared $(\boldsymbol{C})$, and rearing (D). $\boldsymbol{E}$, Light and dark test to measure time spent in bright field $(\boldsymbol{E})$ and latency to enter bright field ( $\boldsymbol{F} ; n=11$ for both WT $\mathrm{FLR}$ and FIr). Unpaired $t$ test was used for statistical analysis; ${ }^{*} p \leq 0.05,{ }^{* *} p \leq 0.001$. Error bars represent \pm SEM.

feature of Flr behavior as compared with that of the $\mathrm{WT}_{\mathrm{FLR}}$ strain was the frequency and completeness of their spontaneous bouts of self-grooming (Fig. $1 A$; Movies 1, 2). Individual bouts could last up to 6 min and the sequence of this grooming behavior in FIr was nearly identical to the normal syntactical behavior described by Berridge and Whishaw (1992) for rats. This behavior is regularly associated with high anxiety in mice. Because this behavior involved full-body grooming by Flr, it did not cause the loss of head-fur as has been described for several mice strains with SAPAP or Shank3 deletions (Welch et al., 2007; Peça et al., 2011). In addition, we made use of the elevated plus-maze (McNaughton et al., 2008) and found no significant difference in the entries into the open arms between FIr and $\mathrm{WT}_{\mathrm{FLR}}$ mice (Fig. 1B). However, Flr mice spent significantly less time in the open arms compared with WT mice, suggesting increased anxiety (Fig. 1C). Rearing in the closed arms, considered an exploratory behavior, was also significantly decreased in Flr versus $\mathrm{WT}_{\mathrm{FLR}}$ (Fig. 1D), but frequencies of head dips in the open arm, considered a risk-taking behavior (McFarlane et al., 2008; McNaughton et al., 2008), were similar in FIr and $\mathrm{WT}_{\mathrm{FLR}}$ (data not shown). Lastly, we tested the animals in a light/ dark paradigm (Costall et al., 1989). We found that Flr animals spent less time in the bright field (Fig. 1E) and showed a higher latency to enter the dark field (Fig. $1 F$ ) than $\mathrm{WT}_{\mathrm{FLR}}$ animals. Together, our results demonstrate that Flr animals show strong anxiety and repetitive behaviors.

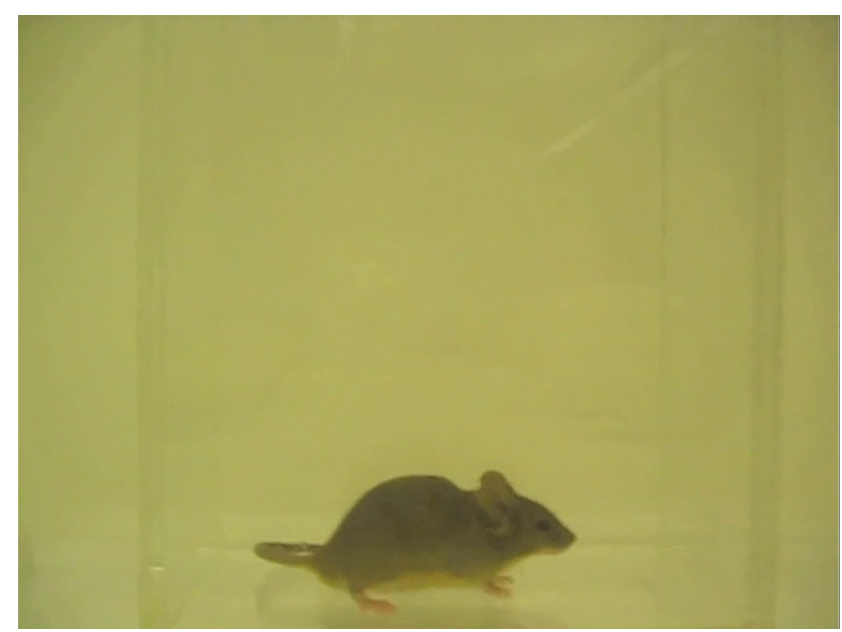

Movie 1. Recording of grooming behavior of $\mathrm{WT}_{\mathrm{FLR}}$ animal. Recording was performed in the dark cycle for $1 \mathrm{~h}$ in a plexiglass cubicle to illustrate details. [View online] 


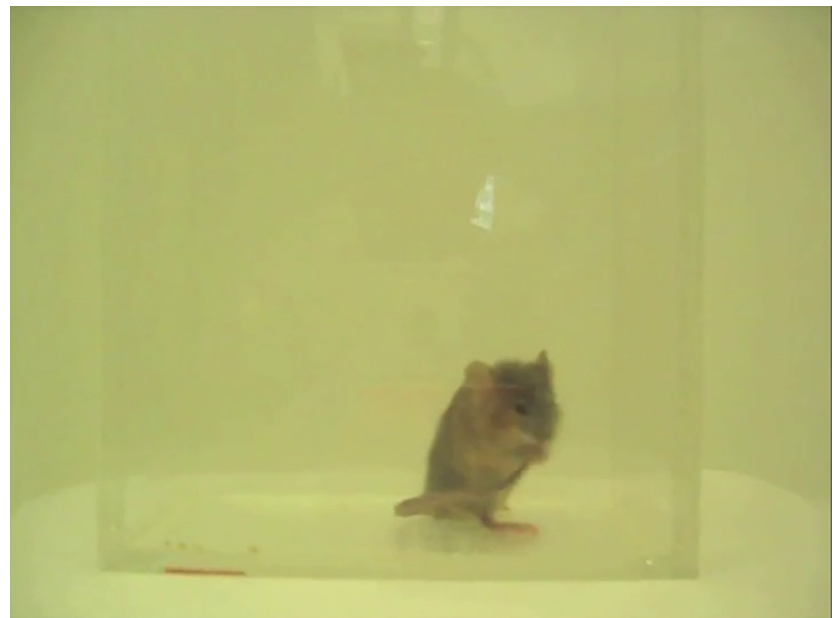

Movie 2. Recording of grooming behavior FIr animal. Recording was performed in the dark cycle for $1 \mathrm{~h}$ in a plexiglass cubicle to illustrate details. [View online]
Another characteristic behavior of ASD phenotypes is the lack of aptitude to perform social interactions. To determine FIr's ability to interact socially we used the threechamber social interaction test (Bolivar et al., 2007; McFarlane et al., 2008; Defensor et al., 2011). In the threechamber social interaction test WT FLR $_{\text {and FIr mice spent }}$ approximately the same amount of time with the novel mouse (NM) and less but insignificantly different times in the chamber with the novel object (NO; Fig. 2A). Interestingly, when we reviewed the behavior of the mice in the chamber with the NM in detail and blinded to strain difference, we found that Flr spent significantly less time than the $\mathrm{WT}_{\mathrm{FLR}}$ adjacent to the NM (Fig. 2B) and if adjacent to the NM, Flr spent most of its time grooming (Movies 3, 4). To gain insight into this behavior, we tested for direct interactions by quantifying social sniffing between animals. Flr/FIr or $\mathrm{WT}_{\mathrm{FLR}} / \mathrm{WT}_{\mathrm{FLR}}$ pairs were contained in a clear rectangular chamber $(7 \times 14 \times 30 \mathrm{~cm})$ that required some physical contact between the animals (Defensor et al., 2011). FIr pairs
A

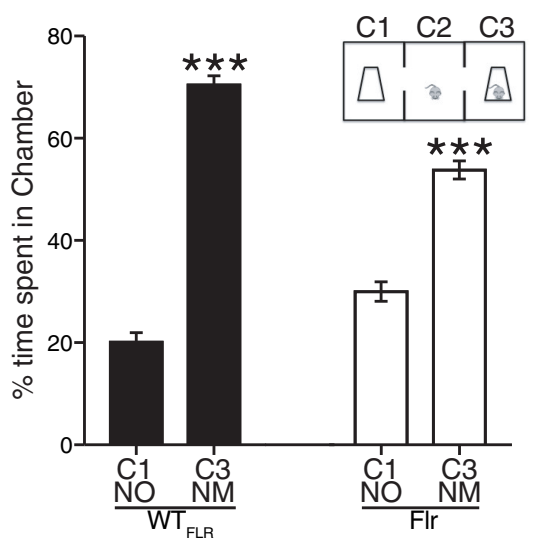

C

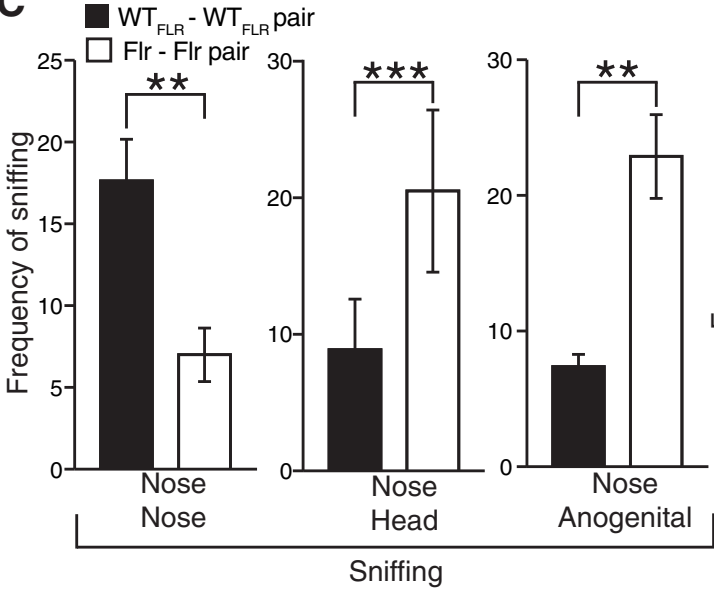

B

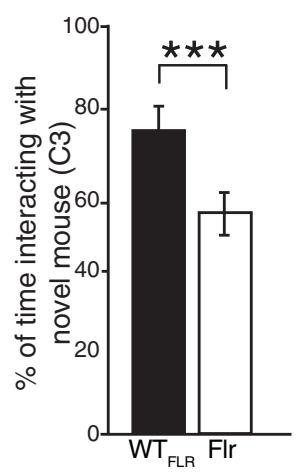

D

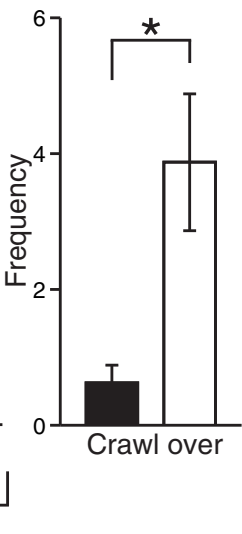

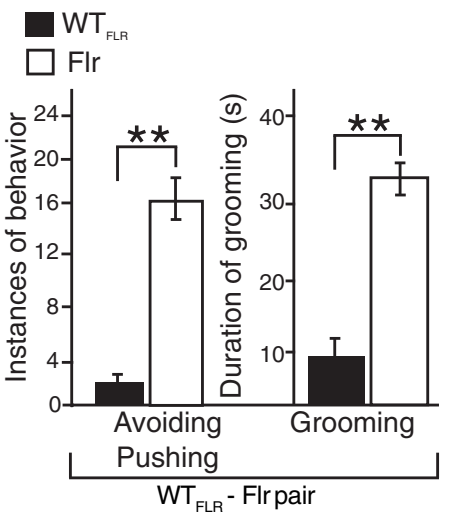

Figure 2. Atypical social interactions in Flr mice. A, Three-chamber social approach test where a caged NM in chamber 3 (C3) and a NO in chamber 1 (C1) were placed ( $n=17$ for both $\mathrm{WT}_{\mathrm{FLR}}$ and Flr). B, Percentage of time spent interacting with NM (sniffing and close proximity to the NM cage; Movies 3, 4). $\boldsymbol{C}$, Social proximity test with Flr-Flr and WT $\mathrm{FLR}^{-\mathrm{WT}_{\mathrm{FLR}}}$ pairs. The behaviors measured were nose tip-to-nose tip sniffing (with/without contact; NN), NH sniffing, NA sniffing ( $n=20$ for both WT FLR $_{\text {and }}$ Flr). $\boldsymbol{D}$, Social proximity test with Flr-WT $\mathrm{FLR}_{\mathrm{F}}$ pairs Flr to quantify avoiding/pushing and grooming behaviors (Movies 5 , 6). Unpaired $t$ test and sum-rank test was used for statistical analysis; ${ }^{*} p \leq 0.05,{ }^{* *} p \leq 0.001,{ }^{* * *} p \leq 0.0001$. Error bars represent \pm SEM. 


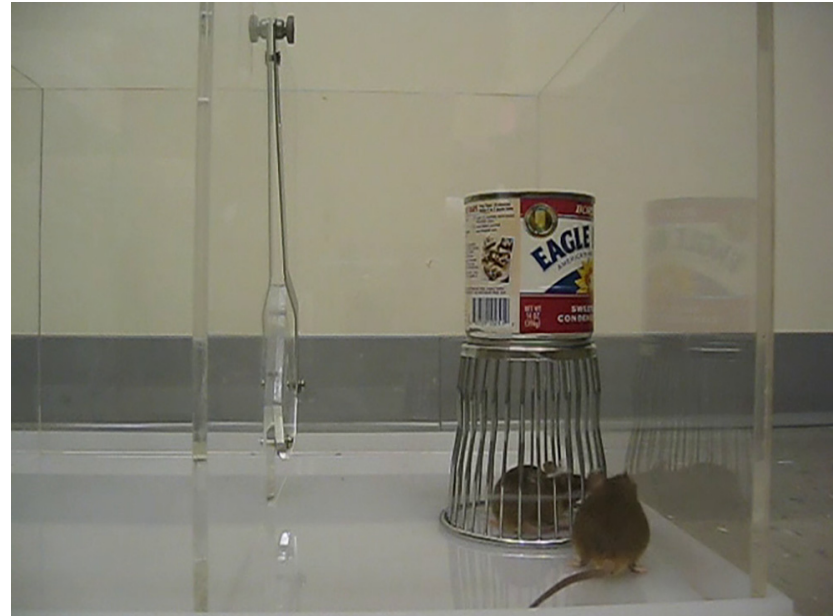

Movie 3. Recording of $\mathrm{WT}_{\mathrm{FLR}}$ animal in the three-chamber social test. Animals were recorded for $10 \mathrm{~min}$ to determine social interaction. $\mathrm{WT}_{\mathrm{FLR}}$ animals spend more time interacting with the novel animal than NO. [View online]

showed a significant reduction in nose-to-nose (NN) sniffing compared with $\mathrm{WT}_{\mathrm{FLR}}$ pairs. There were also significant increases among FIr pairs compared with $\mathrm{WT}_{\mathrm{FLR}}$ pairs in nose-to-anogenital (NA) sniffing and in nose-to-head $(\mathrm{NH})$ sniffing. The latter might reflect attempts of Flr to avoid accidental nose-to-nose contact, a possibility consistent with the additional finding that crawl-over (CO) behavior by the recipient mouse, which avoids $\mathrm{NN}$ and $\mathrm{NH}$ sniffing, was also significantly increased in Flr pairs compared with $\mathrm{WT}_{\mathrm{FLR}}$ pairs (Fig. $2 C)$. To establish that general olfactory behavior was not disrupted in Flr, animals were tested in isolation for non-social sniffing behavior. Both $\mathrm{WT}_{\mathrm{FLR}}$ and Flr spent similar amounts of time sniffing a water-saturated wick, and, in a separate exposure, a vanilla extract saturated wick, suggesting that general olfactory behavior of the strains was not perturbed (data not shown). Our data suggest that Flr/Flr pairs actively avoid head region

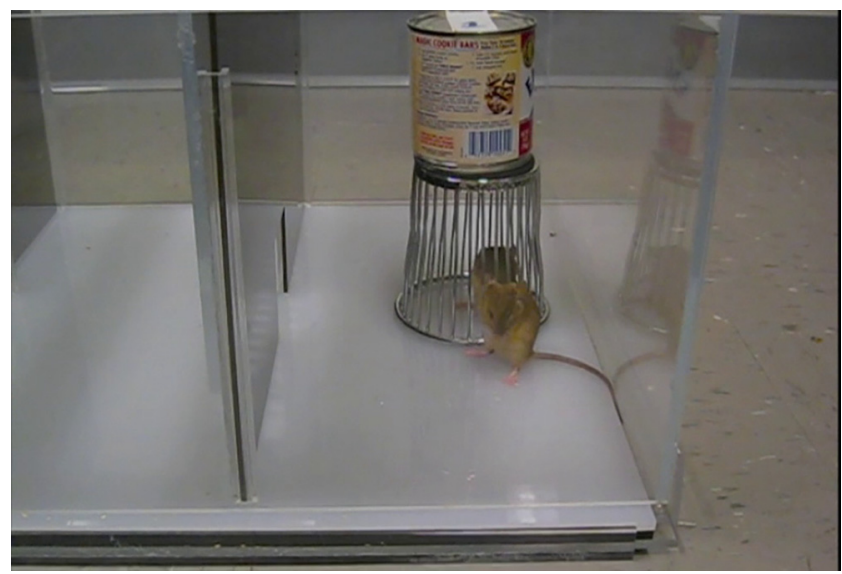

Movie 4. Recording of Flr animal in the three-chamber social test. Animals were recorded for $10 \mathrm{~min}$ to determine social interaction. Flr animals spend more time close to novel animal than NO, but its time is spent grooming. [View online]

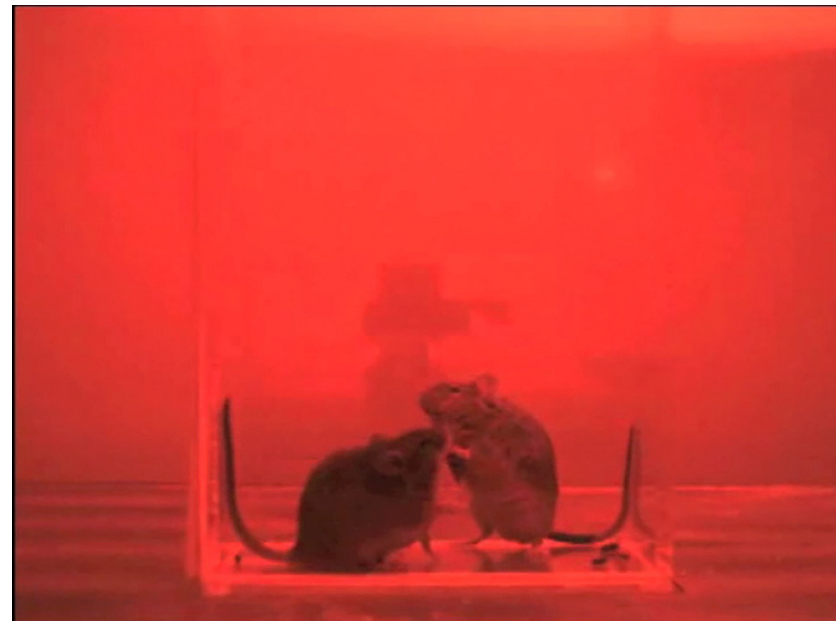

Movie 5. Recording of FIr/WT $\mathrm{FLR}_{\mathrm{FR}}$ pairs in a proximity box to demonstrate avoidance behaviors by Flr. When in close contact FIr animals turn their head abruptly to avoid contact. [View online]

close contact (Fig. 2C). To test this hypothesis, we

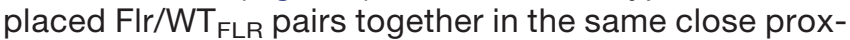
imity box, reasoning that if $\mathrm{WT}_{\mathrm{FLR}}$ mice persisted in head region contact FIr might demonstrate a more obvious avoidance behavior. We found that the FIr member of each pair avoided the $\mathrm{WT}_{\mathrm{FLR}}$ sniffing near the head by turning away abruptly, or actively, with forepaws pushing the $\mathrm{WT}_{\mathrm{FLR}}$ away (Fig. 2D; Movies 5, 6). Moreover, Flr animals also engaged in significantly more instances of grooming-onset during this 2-min interval compared with $\mathrm{WT}_{\mathrm{FLR}}$ (Fig. 2D), suggesting an increase in anxiety. Together, our data indicate that Flr animals display severe social deficits, avoiding repeatedly and strongly contact with other animals.

To test whether memory formation in Flr animals is disrupted, we conducted the Morris water maze test and fear

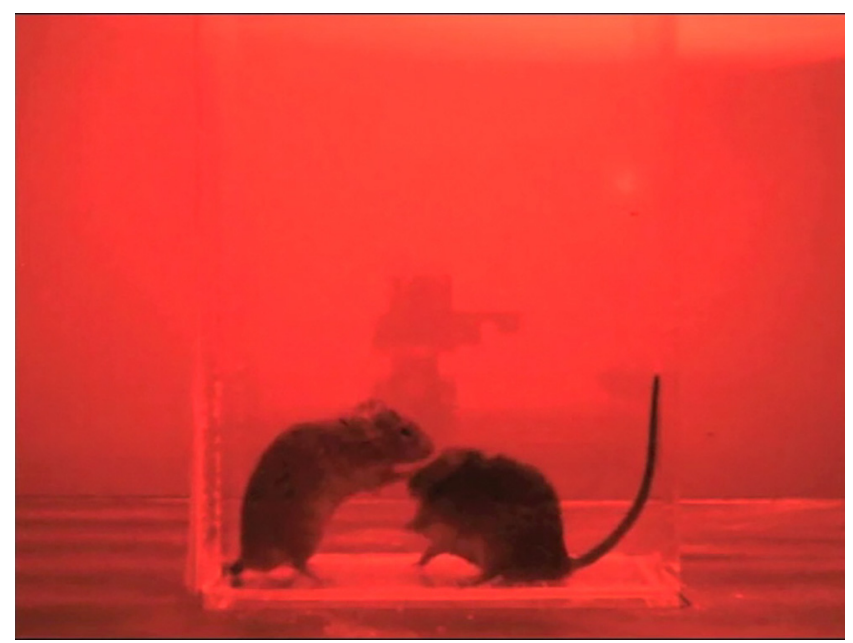

Movie 6. Recording of Flr/WT $\mathrm{FLR}_{\mathrm{F}}$ pairs in a proximity box to demonstrate avoidance behaviors by Flr. When in close contact FIr animals actively pushes $\mathrm{WT}_{\mathrm{FLR}}$ animal with forepaws to avoid contact. [View online] 
A
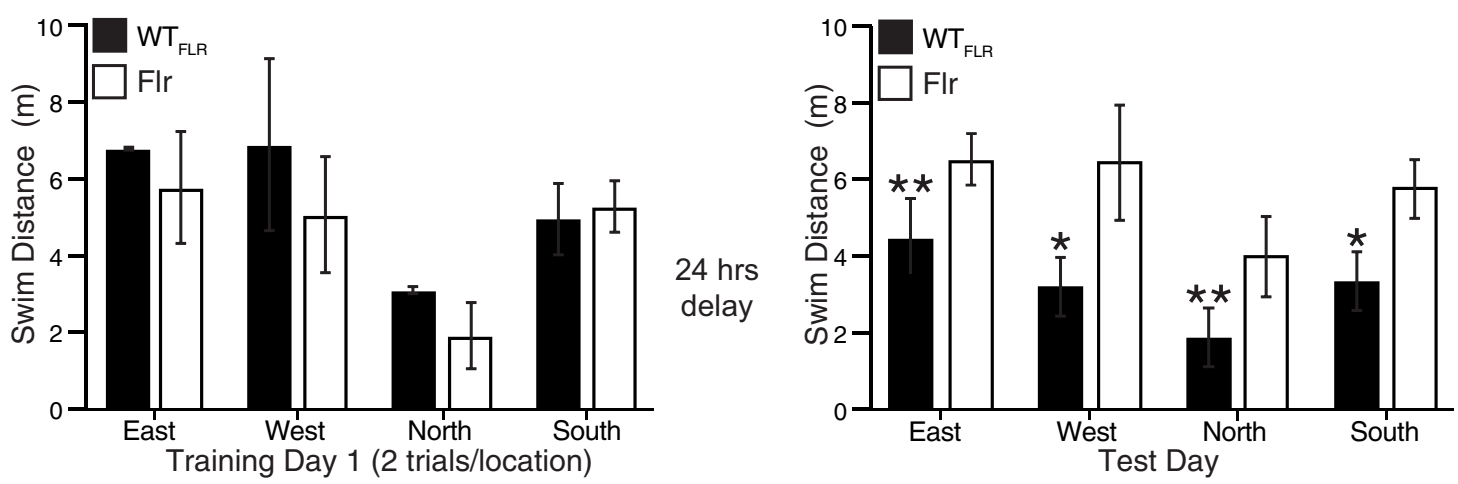

B

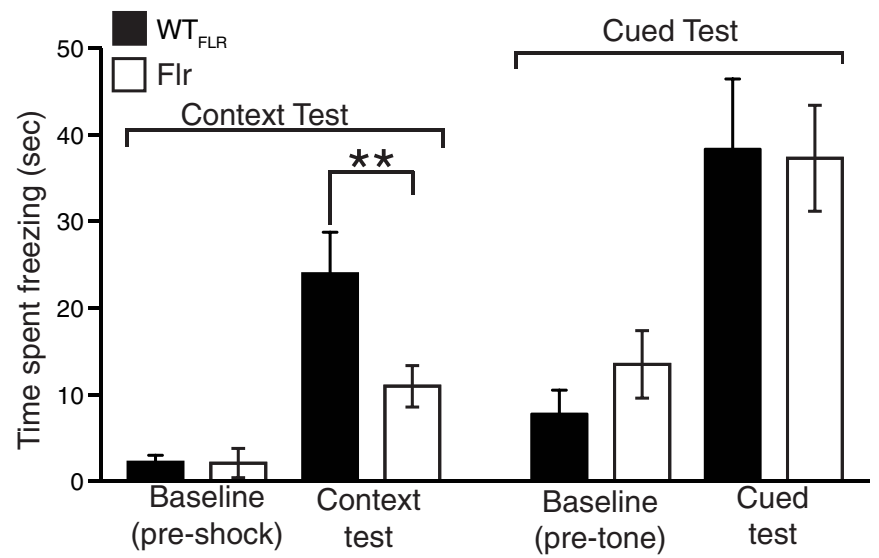

Figure 3. FIr mice show deficient hippocampus dependent-spatial memory formation. $\boldsymbol{A}$, Morris water maze on $\mathrm{WT}_{\mathrm{FLR}}$ and Flr animals on training and test days ( $n=9,8$ trials per animal on each training day). Animals were dropped in four different locations East, West, North, or South. After 24-h delay on test day, WT $_{\mathrm{FLR}}$ travels a significantly shorter distance to reach platform compared with training day. $\boldsymbol{B}$, Context-dependent and cued fear (85- $\mathrm{dB}$ noise) conditioning paradigms of $\mathrm{WT}_{\mathrm{FLR}}$ and Flr animals. Unpaired $t$ test was used to compare within a group between training and test day. One-way ANOVA was used to compare between groups. Error bars represent $\pm \mathrm{SEM} ;{ }^{*} p \leq 0.05,{ }^{* *} p \leq 0.001$.

conditioning tests. For spatial memory each FIr or $\mathrm{WT}_{\mathrm{FLR}}$ mouse was trained during repeated 60 -s periods to find a submerged platform in an environment with distinct visual cues. Four different drop zones were used (North, South, East, West) and training was conducted until all mice found the submerged platform with similar efficiency (Fig. $3 A$, training day). Retention of the platform's position was tested $24 \mathrm{~h}$ later. In this test, Flr mice failed to retain the memory of the platform position: they spent significantly less time in the quadrant containing the platform and covered significantly longer swim distances to reach the platform compared with $\mathrm{WT}_{\mathrm{FLR}}$ (Fig. $3 A$, test day). Average swim speed (meters per second) was not significantly different between FIr mice and $\mathrm{WT}_{\mathrm{FLR}}$ (FIr $0.1 \mathrm{~m} / \mathrm{s}$ and $\mathrm{WT}_{\mathrm{FLR}}$ $0.09 \mathrm{~m} / \mathrm{s}$ ). In addition, we tested memory formation dependent on either hippocampus or amygdala using the fear-conditioning paradigm based on context or cue, respectively. Each individual mouse was placed in a test box with a floor that could deliver a short electric shock (MED Associates). All mice explored the environment with little or no freezing. For hippocampal-dependent memory formation, in a second individual introduction to the box, every mouse received a 2-s, 0.6-mA electric shock to its feet (Fig. 3B, context test, baseline). When each mouse was subsequently re-introduced to the box, Flr mice showed a significant decrease in freezing compared with $\mathrm{WT}_{\mathrm{FLR}}$ (Fig. 3B, context test), suggesting defects in hippocampal dependent learning/memory. To test for amygdala-dependent memory formation caused by fear, the apparatus consisted of the same box plus an $85 \mathrm{~dB}$. burst of noise delivered before the shock. Both Flr and $\mathrm{WT}_{\mathrm{FLR}}$ mice were first tested with a noise stimulus and a shock. Both strains of mice responded with freezing, and no significant difference was observed between Flr and $\mathrm{WT}_{\mathrm{FLR}}$ (Fig. $3 B$, cued test, baseline). Animals were reintroduced to the box after $\sim 2 \mathrm{~h}$ and given the sound cue without the shock. Both Flr and $\mathrm{WT}_{\mathrm{FLR}}$ spent approximately the same time freezing, indicating that cued-learning was not significantly different between $\mathrm{WT}_{\mathrm{FLR}}$ and FIr (Fig. 3B, cued test). Together, our data indicate that Flr has severe hippocampal-dependent memory formation deficits and that fear-conditioned memory formation dependent on the amygdala is not affected. 
A

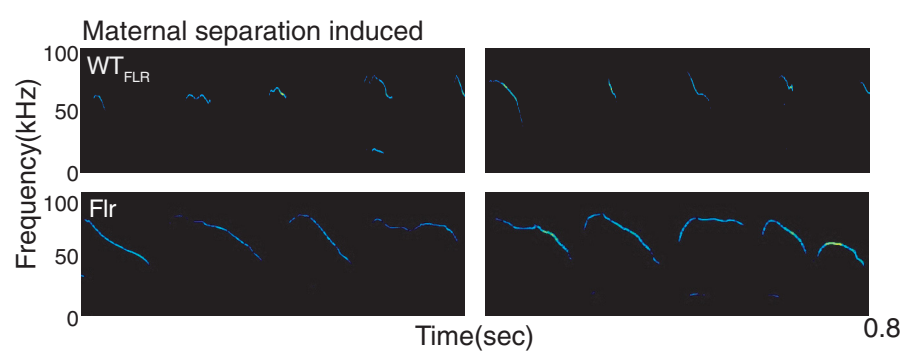

C

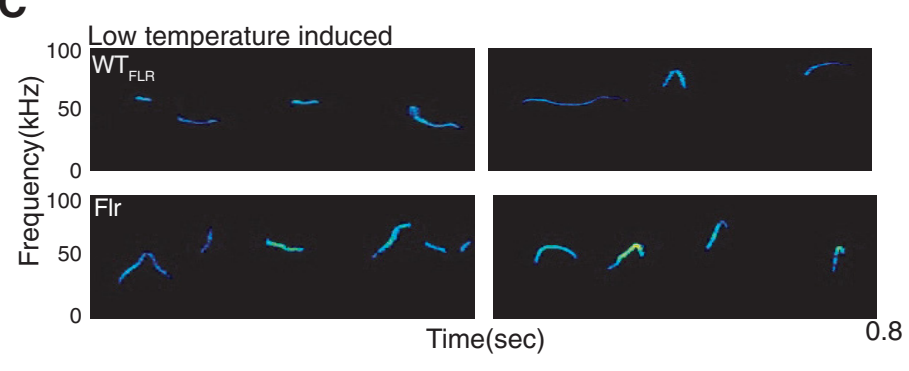

B
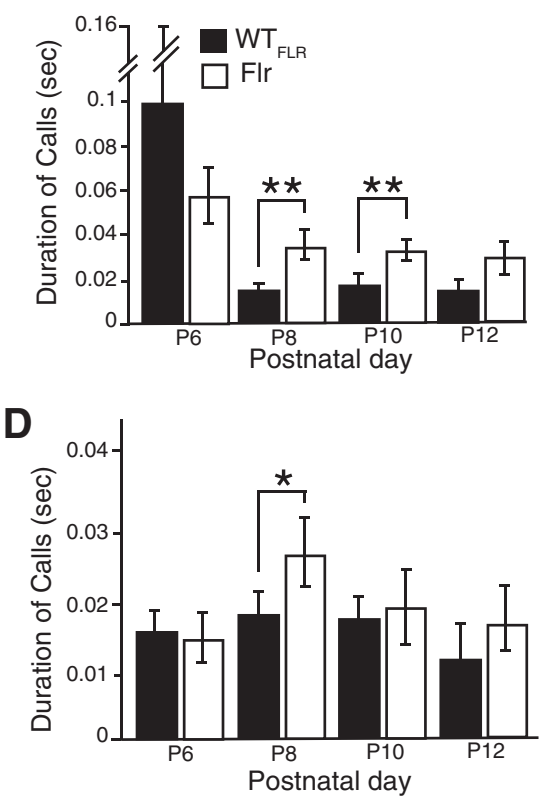

Figure 4. Communication deficits in FIr mice. $\boldsymbol{A}$, Representative spectrograms of a P8 pup during maternal separation. $\boldsymbol{B}$, Maternal isolation induced USV on P8 and P10 ( $n=10$ for both $\mathrm{WT}_{\mathrm{FLR}}$ and FIr). FIr showed statistically significant increase in total duration of calls. $\boldsymbol{C}$, Representative spectrogram of P8 pup USV during cold-temperature-induced vocalization. $\boldsymbol{D}$, Cold temperature-induced USV ( $n=10$ for both $\mathrm{WT}_{\mathrm{FLR}}$ and FIr). Flr showed statistically significant increase in total duration of calls on P8. Unpaired non-parametric $t$ test was used for statistical analysis. Error bars represent $\pm \mathrm{SEM} ;{ }^{*} p \leq 0.05,{ }^{* *} p \leq 0.001$.

Another characteristic behavior observed for ASD mouse models is an increase in the duration of ultrasonic vocalizations (USVs) (Wöhr et al., 2011). This abnormal vocalization has been observed in BTBR $T+t f / J$ and Shank1 mutants, two models of ASD (Scattoni et al., 2008; Wöhr et al., 2011). To test whether Flr mice also display any defect in vocalization phenotype, we evaluated changes in USVs in FIr and WT FLR pups after separating individuals from their mothers and littermates or after exposing isolated pups to low temperatures. Under separation conditions, all mouse pups produced infrequent and relatively long calls starting on P6. However, when the same pups were tested again at $\mathrm{P} 8$, and $\mathrm{P} 10$, isolated from their mothers and littermates, the duration of the Flr pup calls were invariably longer than those of $\mathrm{WT}_{\mathrm{FLR}}$ (Fig. $4 A, B)$. No changes in call frequency was observed. In addition, calls induced by low-temperature isolation also had longer durations in FIr than in $\mathrm{WT}_{\mathrm{FLR}}$ but only at P8 (Fig. 4C,D). Taken together, our data show severe behavioral deficits of FIr animals, similar to what has been observed in mice with anxiety or ASD like phenotypes.

\section{FIr animals are deficient in the transport of synaptic components to the PSD}

Next, we asked whether the severe changes in animal behavior observed in FIr are caused by the diminished transport of synaptic components to the PSD. The imaging analyses of Gerrow et al. (2006) and Moutin et al. (2012) demonstrated that glutamate synapse scaffolding molecules, SAPAP (GKAP), Shank and the membrane- associated guanylate kinase (MAGUK) PSD-95, travel as a complex up dendritic shafts and then up spine necks to the PSDs at the spine tip. In Flr, a significant amount of synaptic cargo gets transferred to a dimer of the truncated MyoVA cargo-binding domain (e.g., the FIr protein). These abnormal myosins, lacking the end-feet with ATP hydrolyzing heads of $\mathrm{WT}_{\mathrm{FLR}}$ MyoVA, cannot step along the actin filaments to the PSD. However, it is possible than more than one MyoVa motor attaches to a single transport vesicle and moves in a straight line along an actin filament (Hammer and Sellers, 2011). This would account for the presence of Flr protein $(\sim 85 \mathrm{kDa})$ in Flr mouse synaptosomes (Fig. 5A1). However, WT MyoVA carrying some of the scaffolds attached to the Flr protein cargo could be slowed down or unable to move to the PSD. This would account for the decrease in WT MyoVA found in Flr synaptosomes (Fig. 5A1,A2).

To characterize changes in transport of synaptic components in FIr neurons, we compared the levels of proteins between $\mathrm{WT}_{\mathrm{FLR}}$ and Flr synaptosomes using quantitative Western blotting for 15 synaptic proteins. (1) Known MyoVA synapse-associated cargos: the mRNA binding protein TLS/FUS (Yoshimura et al., 2006), the IP3R (Takagishi et al., 1996; Miyata et al., 2011), and FMRP. (2) The major mature glutamate synapse scaffold complex, namely, PSD-95, SAPAP, and Shank (Gerrow et al., 2006; Moutin et al., 2012) and molecules closely related to PSD-95, namely, the MAGUKS PSD-93 and SAP102 (Nithianantharajah and Grant, 2013) and Homer1c known to be directly associated with Shank at synapses (Tu et al., 1999). (3) The 

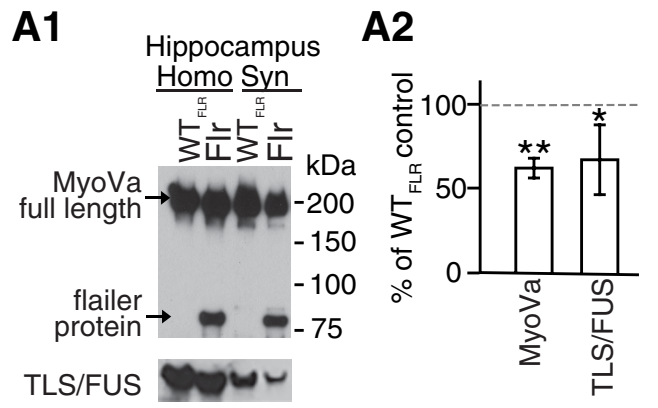

C1

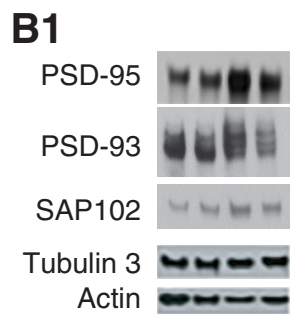

\section{B2}

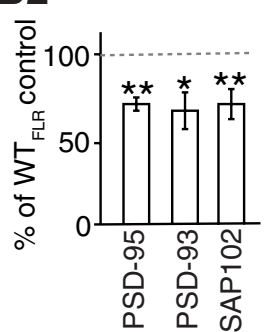

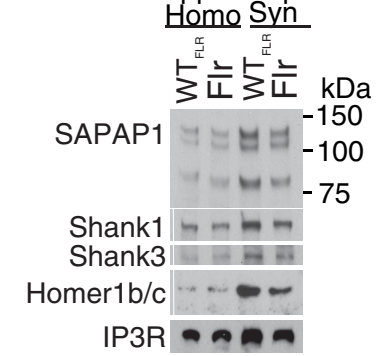

D1

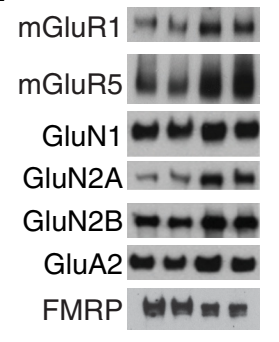

C2

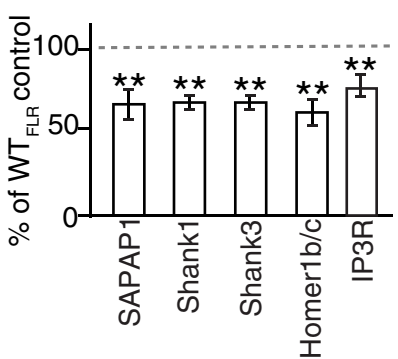

D2

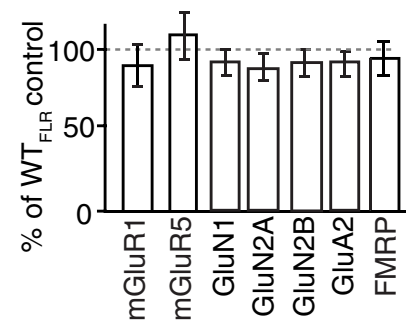

Figure 5. Synaptic transport of proteins to PSD is altered in FIr mice. $\mathrm{WT}_{\mathrm{FLR}}$ and FIr hippocampal synaptosome extracts were used for quantitative Western blot analyses of synaptic proteins. A1, A2, Levels of full-length MyoVa and TLS/FUS were reduced in FIr extracts. B1, B2, Expression levels of major MAGUKs (PSD-95, PSD-93, SAP102) and (C1, C2) SAPAP1, SHANK1, SHANK3, Homer1b/c, and IP3R were significantly reduced in Flr. D1, D2, mGluRs, NMDAR, AMPAR subunit levels, and FMRP were not changed in Flr when compared with $\mathrm{WT}_{\mathrm{FLR}}$. Homogenate (Homo) and synaptosome (Syn) was prepared from whole hippocampus. Protein levels in Flr were quantified and plotted as \% of $\mathrm{WT}_{\mathrm{FLR}} ; n=3$ samples per group/each sample pool three to five animals. Unpaired $t$ test was used for statistical analysis. Error bars represent $\pm \mathrm{SEM} ;{ }^{*} p \leq 0.05,{ }^{* *} p \leq 0.001$.

major glutamate receptors or glutamate receptor subunits, namely, mGluR1, mGluR5, GluN1, GluN2A, GluN2B, and GluA2. Nine of these proteins TLS/FUS (Fig. 5A1,A2), PSD-95, PSD-93, SAP102 (Fig. 5B1,B2), SAPAP, Shank1, Shank3, Homer 1C, IP3R (Fig. 5C1, C2) showed significant reductions in their expression in Flr synaptosomes compared with synaptosomes from $\mathrm{WT}_{\mathrm{FLR}}$ mice. However, all glutamate receptors and receptor subunits tested (mGluR1, mGluR5, GluN $1,2 \mathrm{~A}, 2 \mathrm{~B}, \mathrm{~A} 2$ ) as well as the FMRP protein, were not significantly different in synaptosome levels between $\mathrm{WT}_{\mathrm{FLR}}$ and FIr (Fig. 5D1,D2). Together, we found a significant reduction on the expression of the scaffolding complexes in synaptosomes of Flr neurons. Conversely, all receptors subunits studied did not show changes in the expression of proteins in Flr synaptosomes. This could be caused by the abnormal clustering of receptors at dendritic shafts (Yoshii et al., 2013) that might have rounded as vesicles and precipitated along with synaptosomes. The changes observed in synaptic composition because of the deficient transport by MyoVa could in fact explain the behavioral deficits observed in FIr mice shown above.

\section{mGLuR-dependent LTD, but not LTP, is impaired in FIr mutants}

We have previously shown that greater than six-monthold FIr animals have impaired LTD in visual cortex slices, indeed showing a small LTP response in its place (Yoshii et al., 2013). Many studies have proposed that synaptic plasticity phenomena such as LTP and LTD are the main mechanisms that control memory formation (Nabavi et al., 2014). Here, we have shown that Flr animals have impaired hippocampal-dependent memory formation (Fig. 3), which could be a consequence of the lack of synaptic plasticity phenomena such as LTD. For this reason, we asked whether LTP and LTD at the Schaffer collateral (SC) to CA1 pyramidal synapse (SC-CA1) is altered in Flr mice.

To study fLTP in CA1 pyramids, we induced LTP by SC stimulation using three different protocols: two 1-s 100$\mathrm{Hz}$ bursts at 20-s interburst intervals, involving both NMDARs and some L-type $\mathrm{Ca}^{2+}$ channels; a single 1-s $25-\mathrm{Hz}$ burst known to be dependent only on NMDARs (Cavuş and Teyler, 1996); and saturation LTP, with six $100-\mathrm{Hz}$ stimuli at 5 -min intervals. In all three protocols used to induce LTP, responses between Flr and $\mathrm{WT}_{\mathrm{FLR}}$ animals were indistinguishable, showing no defects in Flr animals (Fig. $6 A-C, n=$ number of slices/number of mice). Conversely, two forms of LTD occur at SC-CA1 synapses. The first group requires mGluR5 activation of phospholipase $\mathrm{C}$ to generate IP3 and diacylglycerol (DAG). IP3 activates the IP3R on SER to release $\mathrm{Ca}^{2+}$ into spine cytoplasm and DAG triggers local protein synthesis (Huber et al., 2000). In WT rodents this form of LTD is induced by stimulating the SC-CA1 inputs with pairedpulses separated by $50 \mathrm{~ms}$ and given at $1 \mathrm{~Hz}$ in the presence of the NMDAR antagonist AP5 (Kemp and Bashir, 1999) or by application of the metabotropic Group1 mGluR agonist DHPG (Palmer et al., 1997). 
A

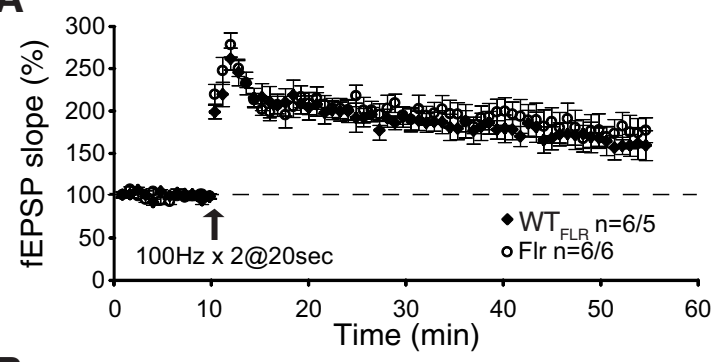

B

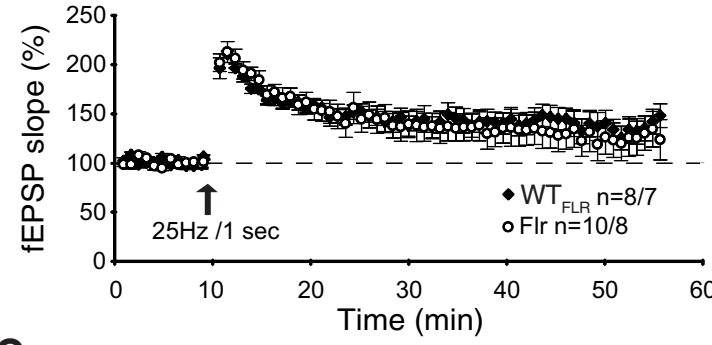

C

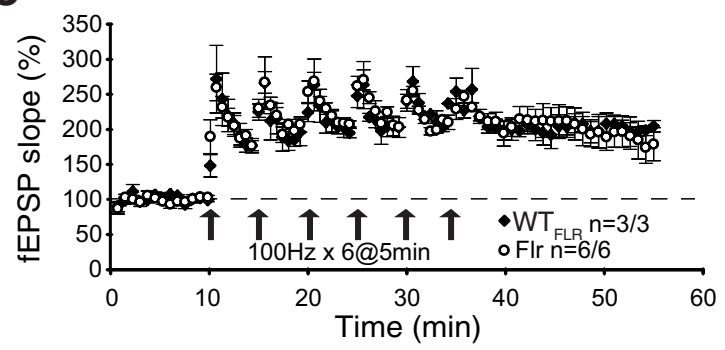

G

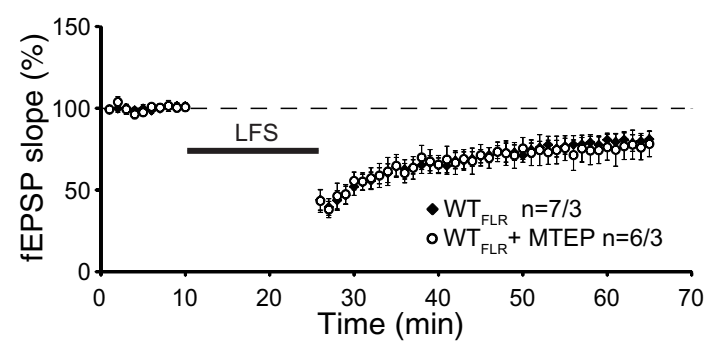

D

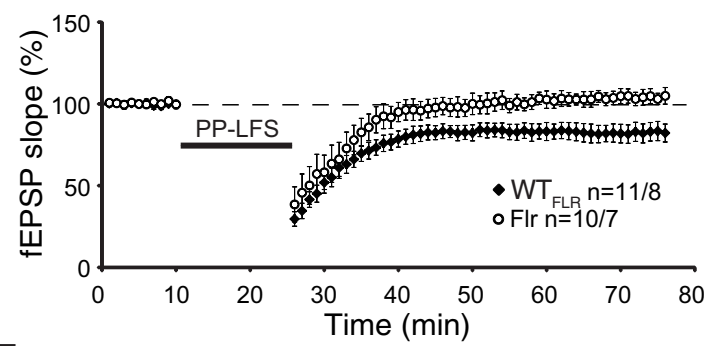

E

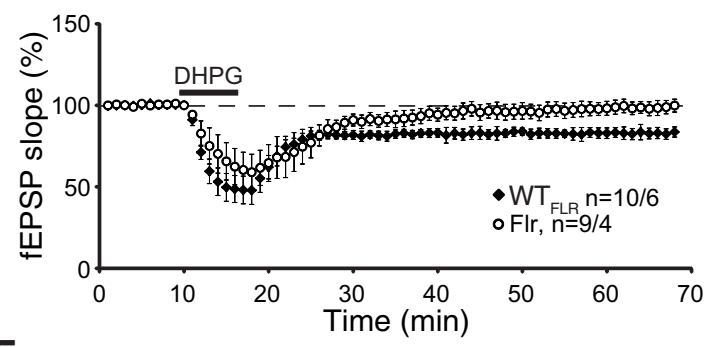

$\mathbf{F}$

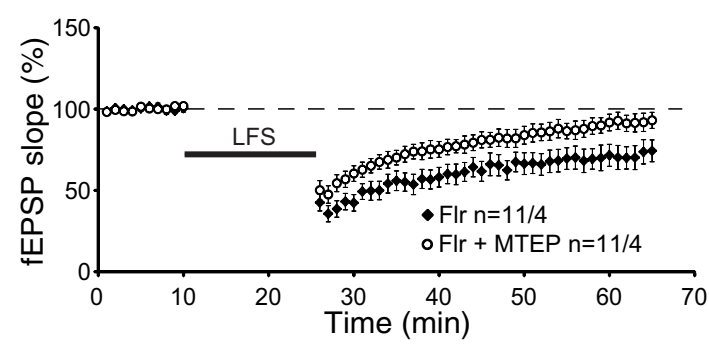

Figure 6. Absence of mGluR-dependent LTD at hippocampal SC to CA1 synapses in Flr mice. Field potentials (fEPSPs) were recorded in the stratum radiatum of CA1 by delivering stimulation to SC pathway in both $\mathrm{WT}_{\mathrm{FLR}}$ and FIr mice. LTP was induced by (A) two 1-s 100-Hz bursts at 20-s interburst interval of 1-s duration and 20-s intertrain interval (arrow); (B) a single 1-s 25-Hz burst (arrow); (C) saturating induction, six 1-s 100-Hz bursts at 5-min interburst intervals (arrows). $\boldsymbol{D}$, mGluR-dependent LTD was induced In the presence of $50 \mu \mathrm{m}$ D-AP5, PP-LFS (black bar; Kemp and Bashir, 1999). E, Chemical induction of LTD using the mGluR agonist DHPG $(50 \mu \mathrm{m})$ applied for 5 min (black bar). $\boldsymbol{F}$, Low-frequency stimulation (LFS) LTD (900 stimuli at $1 \mathrm{~Hz}$, black bar) induced

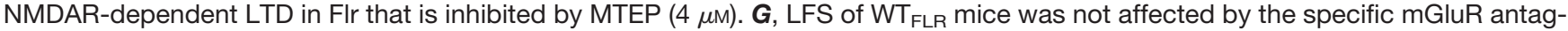
onist MTEP. $\mathrm{n}=$ number of slices/number of mice. Paired $t$ test was used for statistical analysis. Error bars represent \pm SEM.

Both stimulation protocols produced normal mGluR5dependent LTD in $\mathrm{WT}_{\mathrm{FLR}}$ mice (Fig. 6D,E). In contrast, Flr mice showed a small LTP in response to the pairedpulse stimulation protocol and no LTD in response to the agonist DHPG (Fig. 6D,E). To determine the dependency on protein synthesis, we used the protein synthesis inhibitor anisomycin. In $\mathrm{WT}_{\mathrm{FLR}}$ (control) mice mGluR5 LTD was blocked, showing a response similar the induction of LTP ( $n=6$ slices from 5 mice; data not shown). Conversely, Flr animals showed no mGluR5 LTD and a small LTP regardless of whether anisomycin was present $(n=15$ slices from 13 mice without anisomycin; $n=5$ slices from 5 mice with anisomycin; data not shown).

In contrast to mGluR5 LTD, NMDAR-dependent LTD induced by 900 stimuli at $1 \mathrm{~Hz}$ in FIr animals appeared normal (Fig. 6F, black squares), a finding also reported by Schnell and Nicoll (2001) based on recordings from young dilute-lethal mice. However, our data support the hypothesis that since some $\mathrm{WT}_{\mathrm{FLR}}$ MyoVA could reach FIr synapses, there might be low, but sufficient, $\mathrm{Ca}^{2+}$ release through residual IP3R and mGluR5 expression/activity 
(Fig. 5) at the synapses of some cells to facilitate NMDARLTD. Consequently, we tested for an effect of residual mGluR5 facilitation of NMDAR-LTD by applying the highly specific mGluR5 antagonist MTEP (Cosford et al., 2003) to block any remaining mGluR5 activity in slices from Flr mice. We found that MTEP significantly reduced NMDARdependent LTD in these Flr brain slices (Fig. 6F, open circles). This effect was not observed in $\mathrm{WT}_{\mathrm{FLR}}$ mice of the same age (Fig. 6G, overlapped data). This observation precludes any involvement in NMDAR-LTD of residual $\mathrm{Ca}^{2+}$ release from SER or tyrosine phosphorylation of NMDARs by Group1 mGluRs (Heidinger et al., 2002). Instead, these results indicate a mitigating effect of mGluR5 on the disruption of NMDAR-dependent LTD in Flr, resulting from the loss of normal scaffolding proteins.

To confirm our conclusion that the loss of LTD is dependent on mGluR activity, we used a positive allosteric modulator (PAM) of mGluRs, 3-cyano-N-(1,3- diphenyl1H-pyrazol-5-yl) benzamide (CDPPB; Kinney et al., 2005). In tuberous sclerosis Tsc2+/- mutant mice, a wellknown intellectual disability, epilepsy and ASD animal model, the application CDPPB is able to restore normal mGluR-LTD (Auerbach et al., 2011). Consequently, we tested whether incubation of Flr hippocampal slices with CDPPB could rescue mGluR5-LTD defects. We found that pretreatment with CDPPB either applied to the slices for $35 \mathrm{~min}$ before recording (Fig. 7B) or applied for $30 \mathrm{~min}$ before and then during recording (Fig. $7 C$ ) did not restore defective mGluR-LTD in Flr (Fig. 7A-C). Together, our data show that in hippocampal slices Flr animals are able to produce normal LTP but that mGluR5-dependent LTD is severely impaired.

\section{Flr mutants have a reduced number of mature dendritic protrusions in CA1 pyramidal neurons}

In many human and mouse neurodevelopmental disorders, it has been shown an abnormal increase in spine density and filipodia shaped spines (Nimchinsky et al., 2001; Hutsler and Zhang, 2010; Peça et al., 2011; Penzes et al., 2011; Kulkarni and Firestein, 2012; Yoshii et al., 2013). To determine changes in spine morphology and density, we examined CA1 pyramidal cells, visible through expression of Thy1-GFP in this Flr strain (Feng et al., 2000). Five apical dendritic segments, $\sim 15-20 \mu \mathrm{m}$ in length and starting $\sim 150 \mu \mathrm{m}$ from the neuron's soma, from each of eight mature Flr males and eight mature $\mathrm{WT}_{\mathrm{FLR}}$ males, were chosen for quantitative analyses. All scoring of protrusion type was done blinded to the phenotype of the mouse. Flr dendritic shafts had many more irregular, frequently thin protrusions than $\mathrm{WT}_{\mathrm{FLR}}$ neurons (Fig. 8A). We found a significant increase in Flr as compared with $\mathrm{WT}_{\mathrm{FLR}}$ in filopodia density (Fig. $8 A$, arrows, $p=0.02, B$ ); no difference in thin spines (Fig. $8 A$, asterisk, $B$ ) and an increased number of mushroom spines in $\mathrm{WT}_{\mathrm{FLR}}$ compared with FIr (Fig. 8A, arrowheads, $p=0.03$, $B)$. Together, our data indicates that expression of Flr protein leads to deficits in spine density and maturation. We speculate that these defects are caused by defective transport of synaptic proteins shown by the reduced expression of synaptic proteins in synaptosomal fractions
A

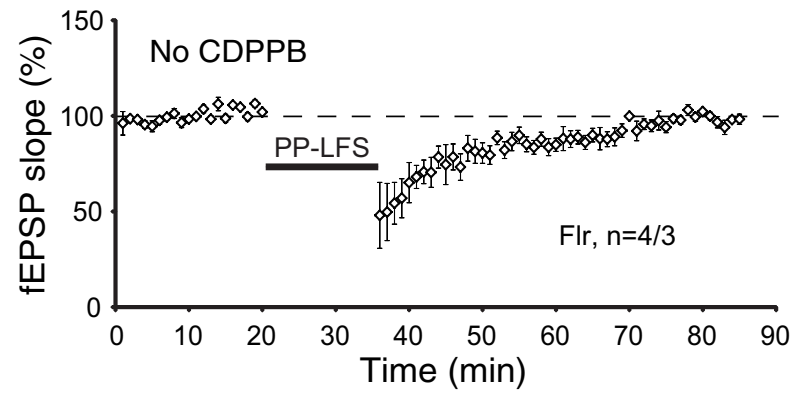

B

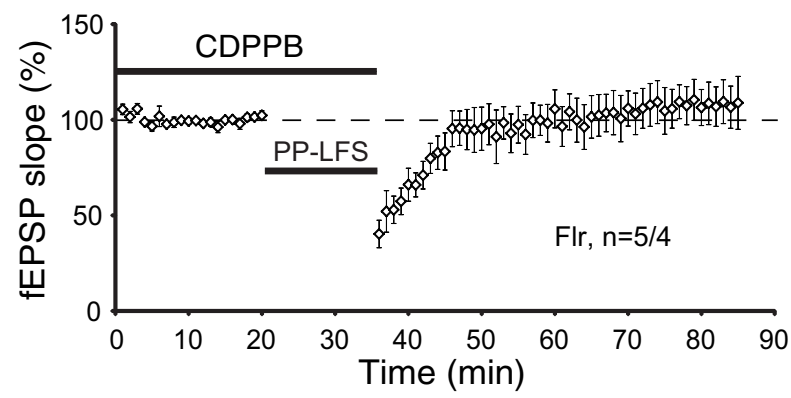

C

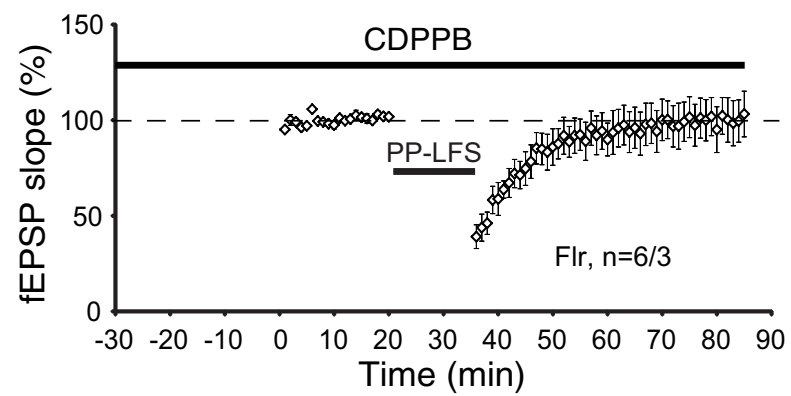

Figure 7. mGluR-dependent LTD is not rescued by mGluR5 agonist CDPPB in Flr mice. $\boldsymbol{A}$, LFS does not induce mGluR-dependent LTD in FIr animals. $\boldsymbol{B}$, CDPPB $(10 \mu \mathrm{M})$ was added to the bath $30 \mathrm{~min}$ before and during LFS induction protocol for LTD. C, CDPPB was added to the bath throughout the experiment, 30 min before, during, and after LFS mGluR-dependent LTD protocol. All recordings above were performed in the presence of $50 \mu \mathrm{M}$ D-AP5. Paired $t$ test was used for statistical analysis. Error bars represent \pm SEM.

(Fig. 5) and by previous data from our laboratory showing mislocalization of synaptic proteins in FIr mice (Yoshii et al., 2013).

\section{Discussion}

MyoVa has many functions in the body, including within the nervous system. MyoVa is a prominent and versatile motor for delivering cargo close to its target zone (Langford, 2002; Yoshimura et al., 2006). Our results report the consequences of disrupting this motor's critical role in establishing proper presynaptic to postsynaptic transfer of neurotransmitter-mediated nervous system information. In all neurons with PSDs on dendritic spine tips MyoVa delivers ribonuclear particles for local synthesis of postsynaptic proteins (Yoshimura et al., 2006) and a 
A
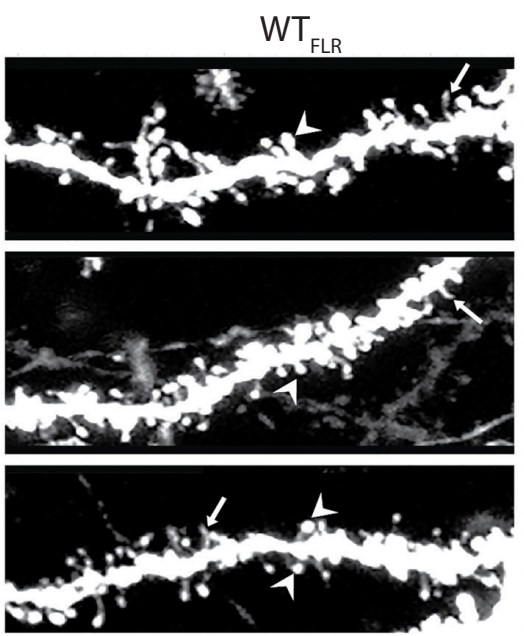

Flr
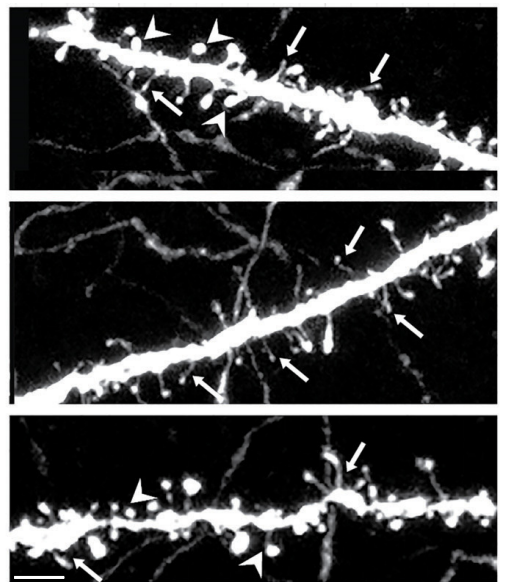

B

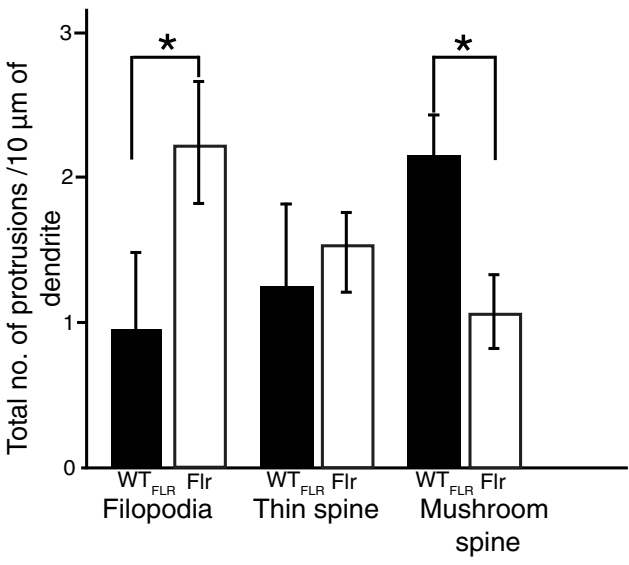

Figure 8. Flr shows increased number of filopodia and decrease in mushroom spines in apical dendrites of hippocampal pyramids. $\boldsymbol{A}$, Representative confocal images of apical dendritic shafts showing filopodia (arrows), thin spines (asterisk) and mushroom spines (arrowheads) in both Flr and $\mathrm{WT}_{\mathrm{FLR}}$. $\boldsymbol{B}$, Quantification of the number of filopodia and mushroom spines in Flr and WT $\mathrm{FLR}(n=8$ animals/genotype and 40 segments of length 15-20 $\mu \mathrm{m})$. The spine analysis and reconstruction were done using autoneuron of neurolucida and contrast increase was done using ImageJ and adobe CC Scale bar: $10 \mu \mathrm{m}$. Unpaired $t$ test with Welch's correction was used for statistical analysis. Error bars represent \pm SEM; ${ }^{*} p \leq 0.05$.

variety of cargos associated with spine PSD components, such as smooth ER, TrkB, mRNA/protein complexes, the molecule PSD-95 and additional scaffolding. All are crucial for normal glutamate depolarization at spine PSDs and postsynaptic cell activation (Naisbitt et al., 2000; Yoshimura et al., 2006; Wagner et al., 2011; Sui et al., 2015). Consequently, in FIr mice homozygous for a dominant-negative MyoVa mutation, the disruption of the transport of these synaptic components causes severe deficits in synaptic function and behavior.

Many analyses of glutamate PSD structure have established the scaffolding system at glutamate synapses (Sheng and Hoogenraad, 2007). Electrophysiological abnormalities such as disruptions in mGluR LTD and changes in dendritic protrusions in the Flr hippocampus as well the abnormal behaviors of Flr mice indicate that this animal's truncated MyoVA causes a phenotype similar in some respects to those of mice that have been genetically engineered to have one of their native scaffolding genes altered to mimic mutations found in humans with ASD or afflicted with other neuropsychiatric syndromes (Welch et al., 2007; McFarlane et al., 2008; Peñagarikano et al., 2011; Peça et al., 2011; Peça and Feng, 2012; Ronesi et al., 2012; Sato et al., 2012). These genes include those encoding proteins that are known cargos of the MyoVA transport system, such as SAPAP, Shank, and PSD-95. One example of a shared abnormal behavior is the self-destructive repetitive behavior that causes mice to lose fur or bloody themselves with compulsive grooming of one body region. This behavior is seen with SAPAP and some SHANK mutations and can be eliminated if SAPAP3 is replaced in the striatum (Welch et al., 2007). Mouse models with Shank mutations produce autismsyndrome-like behaviors (Peça et al., 2011; Wang et al., 2011; Wöhr et al., 2011; Sato et al., 2012; Jiang and Ehlers, 2013). Mutations in PSD-95 itself have been seen in some people with ASD (Feyder et al., 2010; Tsai et al., 2012; Cao et al., 2013). In addition, proteins bound at the synapse by these major scaffolds at the PSD, such as multimerized or long Homers 1b or 1c (Ronesi et al., 2012) and neuroligins (Yu et al., 2011; Baudouin et al., 2012; Wöhr and Scattoni, 2013), are also implicated in human autism or autism-like behaviors in mice. The Flr mouse is significant because it is the only myo5a rodent mutant where the myo5a mutation is brain-specific and the only myo5a mutant that survives throughout adulthood, hence able to show abnormal behavior. In addition, the expression pattern of the flr mutation's promoter (gnb5) has been mapped in the mouse brain (Allen Mouse Brain Atlas), facilitating identification of the contribution of mutation-specific brain regions and to particular behaviors.

The issue of whether the FIr mouse specifically models humans with ASD is complex and impossible to answer at present, since many of the interactions that cause ASD and other neuropsychiatric diseases are unknown. Many mouse mutants with the single mutations seen in autism families show the anxiety, avoidance and disruption of normal vocalizations seen in Flr mice (Figs. 1, 2, 4; Welch et al., 2007; McFarlane et al., 2008; Peça et al., 2011; Peñagarikano et al., 2011). In humans subsequently diagnosed as being on the autism spectrum, early onset seizure with subsequent recovery is often present (Berg et al., 2011; Jeste, 2011), and autistic children are frequently asocial, anxious, show repetitive behaviors and become socially awkward as adults. The Flr mouse shows similar characteristics but its repetitive behavior is elaborate frequently including a full-body grooming sequence. This behavior does not lead to any fur loss since it is not localized similar to what has been seen in other mice models of obsessive compulsive disorder (Welch et al., 2007). Such behavior has not been seen in mouse models carrying single human ASD-associated mutations and might 
reflect an unknown whole-body somatosensory defect. However, we suggest that such a whole-body sensorial defect is unlikely, since Flr/Flr pairs are able to engage in social interactions with their littermates showing excessive nose-to-anal sniffing and contact (Fig. 2C). In addition, the behavior of a Flr mouse in a confined area with a WT mouse is aggressive, as if touching in the head area were sufficiently threatening to a Flr mouse that it needs to push the WT mouse away with its forepaws when approach is near its head (Movies 5, 6). This view is consistent with our findings showing severe anxiety behaviors displayed by Flr mice in the plus maze, and also with the repetitive grooming that occurs whenever Flr mice are in an unfamiliar environment (Fig. 1).

The high expression of gnb5 in dorsal hippocampus motivated us to test Flr and $\mathrm{WT}_{\mathrm{FLR}}$ spatial memory using the water maze and the assay for context-dependent freezing. Flr mice failed in both of these tests that are dependent on spatial memory mediated by the in dorsal (CA1) hippocampus (Morris, 1984; Tsien et al., 1996). Conversely, our experiments using a cued fear-conditioning paradigm dependent mainly on the amygdala (McHugh et al., 2004) showed no difference between Flr and $\mathrm{WT}_{\mathrm{FLR}}$ animals, a finding that correlates with the low expression of gnb5 and consequently of FIr in this brain area.

Our behavioral data demonstrate significant differences between $\mathrm{WT}_{\mathrm{FLR}}$ males and FLR males. We did not asses the behavioral performances of females in these tests. Because there were no detectable sex differences in our biochemical, electrophysiological and morphologic findings, we believe that the likelihood of a sex-specific difference in these behavioral tests is low.

The defects observed in the behavior of FIr mice could be explained by the deficient transport of synaptic proteins and endoplasmic reticulum (ER) to the PSD. Examining synaptosomes from Flr mice, we found that the Homer-IP3 receptor complex that binds to Shank and the MAGUKS (PSD95, PSD93, and SAP102) were significantly reduced (Fig. 5). The IP3 receptor is integrated into the smooth ER membrane, enabling the MyoVa motor protein to pull the entire PSD-95 scaffolding complex with the smooth ER into spine synapses (Hammer and Sellers, 2011), thus explaining the deficient localization at the synapse.

Interestingly, SAP102, the earliest appearing MAGUK, was also reduced. SAP102 is not palmitoylated and therefore cannot travel by vesicular transport (El-Husseini et al., 2000). SAP102 is known to traffic to the synapse of young neurons in association with the NMDAR subunit GluN2B (Washbourne et al., 2004) but might not do so in older neurons such as the ones used in this study. GluN2B was not reduced in Flr relative to $\mathrm{WT}_{\mathrm{FLR}}$ synaptosomes (Fig. 5D1,D2). For this reason, we suggest that defects in synaptic protein synthesis might explain the decreased SAP102 presence at these older hippocampal synapses since SAP102 synthesis has been observed in isolated CA1 hippocampal neuropil (Cajigas et al., 2012). Defects in local protein synthesis could also account for some decreases in PSD-95, PSD-93, and other synaptic proteins we examined. However, it is interesting to note that as techniques for isolating transcripts in neurons have improved more proteins have been found to be synthesized outside of the neuronal cell body in unexpected dendritic and axon compartments (Cajigas et al., 2012; Holt and Schuman, 2013). The local synthesis of PSD-95 but not of FMRP and $\beta$-actin might be defective (Fig. 5) because the granules that transport FMRP and $\beta$-actin mRNAs to the synapse for local protein synthesis are transported by kinesin instead of by myosins and hence might not be affected by the Flr mutation (Davidovic et al., 2007).

Our previous work demonstrated that in mice homozygous for the Flr mutation visual cortical neurons have normal NMDAR-dependent LTP but lack NMDAR-dependent LTD (Yoshii et al., 2013). We also showed that in Fir mice many molecules critical to normal glutamate synaptic function are significantly reduced and misplaced throughout Flr dendritic shafts, including AMPAR subunits, dynamin-3 (critical for AMPAR) and other proteins that undergo endocytosis at synapses (Lu et al., 2007; Morimoto-Tomita et al., 2009; Petrini et al., 2009; Selvakumar et al., 2009; Kato et al., 2010). Our current study shows that in the hippocampus mGluR-dependent LTD was also diminished in Flr animals (Fig. 6) and that positive modulators of mGluR did not revert this aspect of the Flr phenotype (Fig. 7). These observations suggest that the reduced transport and localization of synaptic proteins in FIr animals directly affects the induction of LTD, which cannot be recovered by the solely activation of mGluR. The lack of response to CDPPB was expected in Flr mice, because mGluR5-LTD requires protein synthesis that, in turn, requires long Homer in the glutamate scaffold (to maintain the protein synthesizing machinery near the receptor; Tu et al., 1999) and as seen in Figure 5C. Homer is significantly depleted in Flr synaptosomes.

Disruption of LTD has been widely associated with ASD in mutant mouse models of TSC1, Pcdh10, or Pten (Bateup et al., 2011; Tsai et al., 2012; Takeuchi et al., 2013). The lack of LTD in these mutant animals severely affect developmental activity-dependent synapse elimination or "pruning." The absence of LTD and the consequent hyperconnectivity between neurons in transgenic mice carrying human ASD mutations, suggest that depression and elimination of early axon connections might be a highly vulnerable process in the developing brain. Understanding which connections are sensitive to disruption of this important event and how the disruption causes abnormal behavior will be important steps in mechanistically addressing psychiatric disease. We suggest that the FIr mouse could significantly facilitate this endeavor. Indeed, much of the abnormal FIr behavior we describe as well as the differences in hippocampus synaptosome proteins between Flr versus $\mathrm{WT}_{\mathrm{FLR}}$ mice can be related to the abnormally high level of synaptic function added by LTP but not removed by LTD in this mouse.

The abnormal behaviors of the Flr mutant mouse offer a unique opportunity to explore the importance of LTD and synaptic transport during normal development and behavior. Editing the Flr genome to inactivate at least one copy of the Flr gene should restore both normal MyoVA 
function and a WT phenotype (Bustos et al., 2015; SFN $390.23 / C 18$ ). Then conditional knockouts specific to different neuron types could be used to identify the anatomic pathways and brain areas responsible for the abnormal behaviors of Flr mice. Such information might identify orthologous brain pathways disrupted in human disorders that present with abnormal behaviors comparable to those of Flr mice. Subsequently, studies of the flr gene could facilitate pharmaceutical or behavioral interventions to mitigate or cure some of the most devastating human neuropsychiatric diseases.

\section{References}

Auerbach BD, Osterweil EK, Bear MF (2011) Mutations causing syndromic autism define an axis of synaptic pathophysiology. Nature 480:63-68.

Bateup HS, Takasaki KT, Saulnier JL, Denefrio CL, Sabatini BL (2011) Loss of Tsc1 in vivo impairs hippocampal mGluR-LTD and increases excitatory synaptic function. J Neurosci 31:8862-8869.

Baudouin SJ, Gaudias J, Gerharz S, Hatstatt L, Zhou K, Punnakkal P, Tanaka KF, Spooren W, Hen R, Zeeuw CID, Vogt K, Scheiffele P (2012) Shared Synaptic Pathophysiology in Syndromic and Nonsyndromic Rodent Models of Autism. Science 338:128-132.

Berg AT, Plioplys S, Tuchman R (2011) Risk and correlates of autism spectrum disorder in children with epilepsy: a community-based study. J Child Neurol 26:540-547.

Berridge K, Whishaw I (1992) Cortex, striatum and cerebellum: control of serial order in a grooming sequence. Exp Brain Res 90:275290.

Bolivar V, Walters S, Phoenix J (2007) Assessing autism-like behavior in mice: variations in social interactions among inbred strains. Behav Brain Res 176:21-26.

Bustos FJ, Pandian S, Zhang F, Constantine-Paton M (2015) Use of CRISPRs to remove spontaneous mouse mutation causing abnormal anxiety/autism like behaviors. SFN Abstarcts 390.23/C18.

Cajigas IJ, Tushev G, Will TJ, St D, Fuerst N, Schuman EM (2012) The local transcriptome in the synaptic neuropil revealed by deep sequencing and high-resolution imaging. Neuron 74:453-466.

Cao C, Rioult-Pedotti MS, Migani P, Yu CJ, Tiwari R, Parang K, Spaller MR, Goebel DJ, Marshall J (2013) Impairment of TrkBPSD-95 signaling in Angelman syndrome. PLoS Biol 11:e1001478.

Cavuş I, Teyler T (1996) Two forms of long-term potentiation in area CA1 activate different signal transduction cascades. J Neurophysiol 76:3038-3047.

Correia SS, Bassani S, Brown TC, Lisé M-F, Backos DS, El-Husseini A, Passafaro M, Esteban JA (2008) Motor protein-dependent transport of AMPA receptors into spines during long-term potentiation. Nat Neurosci 11:457-466.

Cosford NDP, Roppe J, Tehrani L, Schweiger EJ, Seiders TJ, Chaudary A, Rao S, Varney MA (2003) 3H]-methoxymethyl-MTEP and $[3 \mathrm{H}]$-methoxy-PEPy: potent and selective radioligands for the metabotropic glutamate subtype 5 (mGlu5) receptor. Bioorg Med Chem Lett 13:351-354.

Costall B, Jones BJ, Kelly ME, Naylor RJ, Tomkins DM (1989) Exploration of mice in a black and white test box: validation as a model of anxiety. Pharmacol Biochem Be 32:777-785.

Defensor EB, Pearson BL, Pobbe RLH, Bolivar VJ, Blanchard DC, Blanchard RJ (2011) A novel social proximity test suggests patterns of social avoidance and gaze aversion-like behavior in BTBR $\mathrm{T}+\mathrm{tf} / \mathrm{J}$ mice. Behav Brain Res 217:302-308.

Durán-McKinster C, Rodriguez-Jurado R, Ridaura C, OrozcoCovarrubias M, Tamayo L, Ruiz-Maldonando R (1999) Elejalde syndrome-a melanolysosomal neurocutaneous syndrome. Arch Dermatol 135:182-186.

Davidovic L, Jaglin XH, Lepagnol-Bestel AM, Tremblay S, Simonneau M, Bardoni B, Khandjian EW (2007) Fragile X mental retardation protein is a molecular adaptor between the neurospecific KIF3C kinesin and dendritic RNA granules. Hum Mol Genet 16:3047-3058.

El-Husseini AE, Craven SE, Chetkovich DM, Firestein BL, Schnell E, Aoki C, Bredt DS (2000) Dual palmitoylation of PSD-95 mediates its vesiculotubular sorting, postsynaptic targeting, and ion channel clustering. J Cell Biol 148:159-172.

Elejalde BR, Holguin J, Valencia A, Gilbert EF, Molina J, Marin G, Arango LA (1979) Mutations affecting pigmentation in man: I. Neuroectodermal melanolysosomal disease. Am J Med Genet 3:65-80.

Feng G, Mellor RH, Bernstein M, Keller-Peck C, Nguyen QT, Wallace M, Nerbonne JM, Lichtman JW, Sanes JR (2000) Imaging neuronal subsets in transgenic mice expressing multiple spectral variants of GFP. Neuron 28:41-51.

Feyder M, Karlsson RM, Mathur P, Lyman M, Bock R, Momenan R, Munasinghe J, Scattoni ML, Ihne J, Camp M, Graybeal C, Strathdee D, Begg A, Alvarez VA, Kirsch P, Rietschel M, Cichon S, Walter H, Meyer-Lindenberg A, Grant SG, et al. (2010) Association of mouse Dlg4 (PSD-95) gene deletion and human DLG4 gene variation with phenotypes relevant to autism spectrum disorders and Williams' syndrome. Am J Psychiatry 167:1508-1517.

Fujii R, Okabe S, Urushido T, Inoue K, Yoshimura A, Tachibana T, Nishikawa T, Hicks GG, Takumi T (2005) The RNA binding protein TLS is translocated to dendritic spines by mGluR5 activation and regulates spine morphology. Curr Biol 15:587-593.

Gerrow K, Romorini S, Nabi SM, Colicos MA, Sala C, El-Husseini A (2006) A preformed complex of postsynaptic proteins is involved in excitatory synapse development. Neuron 49:547-562.

Griscelli C, Durandy A, Guy-Grand D, Daguillard F, Herzog C, Prunieras M (1978) A syndrome associating partial albinism and immunodeficiency. Am J Medicine 65:691-702.

Hammer JA, Sellers JR (2011) Walking to work: roles for class V myosins as cargo transporters. Nat Rev Mol Cell Biol 13:13-26.

Heidinger V, Manzerra P, Wang XQ, Strasser U, Yu SP, Choi DW, Behrens MM (2002) Metabotropic glutamate receptor 1-induced upregulation of NMDA receptor current: mediation through the Pyk2/Src-family kinase pathway in cortical neurons. J Neurosci 22:5452-5461.

Holt CE, Schuman EM (2013) The central dogma decentralized: new perspectives on RNA function and local translation in neurons. Neuron 80:648-657.

Huber KM, Kayser MS, Bear MF (2000) Role for rapid dendritic protein synthesis in hippocampal mGluR-dependent long-term depression. Science 288:1254-1256.

Hutsler JJ, Zhang H (2010) Increased dendritic spine densities on cortical projection neurons in autism spectrum disorders. Brain Res 1309:83-94.

Jeste SS (2011) The neurology of autism spectrum disorders. Curr Opin Neurol 24:132-139.

Jiang YH, Ehlers MD (2013) Modeling autism by SHANK gene mutations in mice. Neuron 78:8-27.

Jhuang H, Garrote E, Mutch J, Yu X, Khilnani V, Poggio T, Steele AD, Serre T (2010) Automated home-cage behavioural phenotyping of mice. Nat Commun 1:68.

Jones JM, Huang JD, Mermall V, Hamilton BA, Mooseker MS, Escayg A, Copeland NG, Jenkins NA, Meisler MH (2000) The mouse neurological mutant flailer expresses a novel hybrid gene derived by exon shuffling between Gnb5 and Myo5a. Hum Mol Genet 9:821-828.

Kato AS, Gill MB, Yu H, Nisenbaum ES, Bredt DS (2010) TARPs differentially decorate AMPA receptors to specify neuropharmacology. Trends Neurosci 33:241-248.

Kemp N, Bashir ZI (1999) Induction of LTD in the adult hippocampus by the synaptic activation of AMPA/kainate and metabotropic glutamate receptors. Neuropharmacology 38:495-504

Kinney GG, O'Brien JA, Lemaire W, Burno M, Bickel DJ, Clements MK, Chen TB, Wisnoski DD, Lindsley CW, Tiller PR, Smith S, Jacobson MA, Sur C, Duggan ME, Pettibone DJ, Conn PJ, Williams DL (2005) A novel selective positive allosteric modulator 
of metabotropic glutamate receptor subtype 5 has in vivo activity and antipsychotic-like effects in rat behavioral models. J Pharmacol Exp Ther 313:199-206.

Kulkarni VA, Firestein BL (2012) The dendritic tree and brain disorders. Mol Cell Neurosci 50:10-20.

Langford GM (2002) Myosin-V, a versatile motor for short-range vesicle transport. Traffic 3:859-865.

Lein ES, Hawrylycz MJ, Ao N, Ayres M, Bensinger A, Bernard A, Boe AF, Boguski MS, Brockway KS, Byrnes EJ, Chen L, Chen L, Chen TM, Chin MC, Chong J, Crook BE, Czaplinska A, Dang CN, Datta S, Dee NR, et al. (2007) Genome-wide atlas of gene expression in the adult mouse brain. Nature 445:168-176.

Lu J, Helton TD, Blanpied TA, Rácz B, Newpher TM, Weinberg RJ, Ehlers MD (2007) Postsynaptic positioning of endocytic zones and AMPA receptor cycling by physical coupling of dynamin-3 to homer. Neuron 55:874-889.

McFarlane HG, Kusek GK, Yang M, Phoenix JL, Bolivar VJ, Crawley JN (2008) Autism-like behavioral phenotypes in BTBR T+tf/J mice. Genes Brain Behav 7:152-163.

McHugh SB, Deacon RM, Rawlins JN, Bannerman DM (2004) Amygdala and ventral hippocampus contribute differentially to mechanisms of fear and anxiety. Behav Neurosci 118:63-78.

McNaughton $\mathrm{CH}$, Moon J, Strawderman MS, Maclean KN, Evans J, Strupp BJ (2008) Evidence for social anxiety and impaired social cognition in a mouse model of fragile $X$ syndrome. Behav Neurosci 122:293-300.

Mercer JA, Seperack PK, Strobel MC, Copeland NG, Jenkins NA (1991) Novel myosin heavy chain encoded by murine dilute coat colour locus. Nature 349:709-713.

Miyata M, Kishimoto $Y$, Tanaka M, Hashimoto K, Hirashima N, Murata Y, Kano M, Takagishi Y (2011) A role for myosin Va in cerebellar plasticity and motor learning: a possible mechanism underlying neurological disorder in myosin Va disease. J Neurosci 31:6067-6078.

Morgans CW, Liu W, Wensel TG, Brown RL, Perez-Leon JA, Bearnot B, Duvoisin RM (2007) Gbeta5-RGS complexes co-localize with mGluR6 in retinal ON-bipolar cells. Eur J Neurosci 26:2899-2905.

Morimoto-Tomita M, Zhang W, Straub C, Cho CH, Kim KS, Howe JR, Tomita S (2009) Autoinactivation of neuronal AMPA receptors via glutamate-regulated TARP interaction. Neuron 61:101-112.

Morris R (1984) Developments of a water-maze procedure for studying spatial learning in the rat. $J$ Neurosci Meth 11:47-60.

Moutin E, Raynaud F, Fagni L, Perroy J (2012) GKAP-DLC2 interaction organizes the postsynaptic scaffold complex to enhance synaptic NMDA receptor activity. J Cell Sci 125:2030-2040.

Moy SS, Nadler JJ, Perez A, Barbaro RP, Johns JM, Magnuson TR, Piven J, Crawley JN (2004) Sociability and preference for social novelty in five inbred strains: an approach to assess autistic-like behavior in mice. Genes Brain Behav 3:287-302.

Munekazu K, Keizo T, Tsuyoshi M (2008) Elevated plus maze for mice. J Vis Exp. Advance online publication. Retrieved December 22, 2008. doi: 10.3791/1088.

Nabavi S, Fox R, Proulx CD, Lin JY, Tsien RY, Malinow R (2014) Engineering a memory with LTD and LTP. Nature 511:348-317.

Naisbitt S, Valtschanoff J, Allison DW, Sala C, Kim E, Craig AM, Weinberg RJ, Sheng M (2000) Interaction of the postsynaptic density-95/guanylate kinase domain-associated protein complex with a light chain of myosin-V and dynein. J Neurosci 20:4524-4534.

Nimchinsky EA, Oberlander AM, Svoboda K (2001) Abnormal development of dendritic spines in FMR1 knock-out mice. J Neurosci 21:5139-5146.

Nithianantharajah J, Grant SGN (2013) Cognitive components in mice and humans: combining genetics and touchscreens for medical translation. Neurobiol Learn Mem 105:13-19.

Palmer MJ, Irving AJ, Seabrook GR, Jane DE, Collingridge GL (1997) The group I mGlu receptor agonist DHPG induces a novel form of LTD in the CA1 region of the hippocampus. Neuropharmacology 36:1517-1532.

Pastural E, Barrat FJ, Dufourcq-Lagelouse R, Certain S, Sanal O, Jabado N, Seger R, Griscelli C, Fischer A, Basile GS (1997)
Griscelli disease maps to chromosome $15 \mathrm{q} 21$ and is associated with mutations in the myosin-Va gene. Nat Genet 16:289-292.

Peça J, Feng G (2012) Cellular and synaptic network defects in autism. Curr Opin Neurobiol 22:866-872.

Peça J, Feliciano C, Ting JT, Wang W, Wells MF, Venkatraman TN, Lascola CD, Fu Z, Feng G (2011) Shank3 mutant mice display autistic-like behaviours and striatal dysfunction. Nature 472:437442.

Peñagarikano O, Abrahams BS, Herman El, Winden KD, Gdalyahu A, Dong $\mathrm{H}$, Sonnenblick LI, Gruver R, Almajano J, Bragin A, Golshani P, Trachtenberg JT, Peles E, Geschwind DH (2011) Absence of CNTNAP2 leads to epilepsy, neuronal migration abnormalities, and core autism-related deficits. Cell 147:235-246.

Penzes P, Cahill ME, Jones KA, VanLeeuwen JE, Woolfrey KM (2011) Dendritic spine pathology in neuropsychiatric disorders. Nat Neurosci 14:285-293.

Petrini EM, Lu J, Cognet L, Lounis B, Ehlers MD, Choquet D (2009) Endocytic trafficking and recycling maintain a pool of mobile surface AMPA receptors required for synaptic potentiation. Neuron 63:92-105.

Prusky GT, Alam NM, Beekman S, Douglas RM (2004) Rapid quantification of adult and developing mouse spatial vision using a virtual optomotor system. Invest Ophthalmol Vis Sci 45:4611.

Rao A, Dallman R, Henderson S, Chen CK (2007) G 5 is required for normal light responses and morphology of retinal ON-bipolar cells. J Neurosci 27:14199-14204.

Ronesi JA, Collins KA, Hays SA, Tsai NP, Guo W, Birnbaum SG, Hu JH, Worley PF, Gibson JR, Huber KM (2012) Disrupted Homer scaffolds mediate abnormal mGluR5 function in a mouse model of fragile X syndrome. Nat Neurosci 15:431-440, S1.

Sanal O, Yel L, Kucukali T, Gilbert-Barnes E, Tardieu M, Texcan I, Ersoy F, Metin A, de Saint Basile G (2000) An allelic variant of Griscelli disease: presentation with severe hypotonia, mentalmotor retardation, and hypopigmentation consistent with Elejalde syndrome (neuroectodermal melanolysosomal disorder). J Neurol 247:570-572.

Sato D, Lionel AC, Leblond CS, Prasad A, Pinto D, Walker S, O'Connor I, Russell C, Drmic IE, Hamdan FF, Michaud JL, Endris V, Roeth R, Delorme R, Huguet G, Leboyer M, Rastam M, Gillberg C, Lathrop M, Stavropoulos DJ, et al. (2012) SHANK1 deletions in males with autism spectrum disorder. Am J Hum Genet 90:879887.

Scattoni ML, Gandhy SU, Ricceri L, Crawley JN (2008) Unusual repertoire of vocalizations in the BTBR $\mathrm{T}+\mathrm{tf} / \mathrm{J}$ mouse model of autism. PLoS One 3:e3067.

Schnell E, Nicoll RA (2001) Hippocampal Synaptic Transmission and Plasticity Are Preserved in Myosin Va Mutant Mice. J Neurophysiol 85:1498-1501.

Selvakumar B, Huganir RL, Snyder SH (2009) S-nitrosylation of stargazin regulates surface expression of AMPA-glutamate neurotransmitter receptors. Proc Natl Acad Sci USA 106:16440-16445.

Sheng M, Hoogenraad CC (2007) The postsynaptic architecture of excitatory synapses: a more quantitative view. Annu Rev Biochem 76:823- 847.

Sui WH, Huang SH, Wang J, Chen Q, Liu T, Chen ZY (2015) Myosin Va mediates BDNF-induced postendocytic recycling of full-length TrkB and its translocation into dendritic spines. J Cell Sci 128:1108-1122.

Takagishi Y, Murata Y (2006) Myosin Va mutation in rats is an animal model for the human hereditary neurological disease, Griscelli syndrome type 1. Ann NY Acad Sci 1086:66-80.

Takagishi Y, Oda SI, Hayasaka S, Dekker-Ohno K, Shikata T, Inouye M, Yamamura H (1996) The dilute-lethal (dl) gene attacks a Ca2+ store in the dendritic spine of Purkinje cells in mice. Neurosci Lett 215:169-172.

Takeuchi K, Gertner MJ, Zhou J, Parada LF, Bennett MVL, Zukin RS (2013) Dysregulation of synaptic plasticity precedes appearance of morphological defects in a Pten conditional knockout mouse model of autism. Proc Natl Acad Sci USA 110:4738-4743. 
Tsai NP, Wilkerson JR, Guo W, Maksimova MA, DeMartino GN, Cowan CW, Huber KM (2012) Multiple autism-linked genes mediate synapse elimination via proteasomal degradation of a synaptic scaffold PSD-95. Cell 151:1581-1594.

Tsien JZ, Huerta PT, Tonegawa S (1996) The essential role of hippocampal CA1 NMDA receptor-dependent synaptic plasticity in spatial memory. Cell 87:1327-1338.

Tu JC, Xiao B, Naisbitt S, Yuan JP, Petralia RS, Brakeman P, Doan A, Aakalu VK, Lanahan AA, Sheng M, Worley PF (1999) Coupling of mGluR/homer and PSD-95 complexes by the Shank family of postsynaptic density proteins. Neuron 23:583-592.

Wagner W, Brenowitz SD, Hammer JA (2011) Myosin-Va transports the endoplasmic reticulum into the dendritic spines of Purkinje neurons. Nat Cell Biol 13:40-48.

Wang X, McCoy PA, Rodriguiz RM, Pan Y, Je HS, Roberts AC, Kim CJ, Berrios J, Colvin JS, Bousquet-Moore D, Lorenzo I, Wu G, Weinberg RJ, Ehlers MD, Philpot BD, Beaudet AL, Wetsel WC, Jiang YH (2011) Synaptic dysfunction and abnormal behaviors in mice lacking major isoforms of Shank3. Hum Mol Genet 20:30933108.

Washbourne P, Liu X-B, Jones EG, McAllister AK (2004) Cycling of NMDA receptors during trafficking in neurons before synapse formation. J Neurosci 24:8253-8264.

Watson AJ, Katz A, Simon MI (1994) A fifth member of the mammalian G-protein beta-subunit family. Expression in brain and activation of the beta 2 isotype of phospholipase C. J Biol Chem 269:22150-22156.

Welch JM, Lu J, Rodriguiz RM, Trotta NC, Peça J, Ding JD, Feliciano C, Chen M, Adams JP, Luo J, Dudek SM, Weinberg RJ, Calakos
N, Wetsel WC, Feng G (2007) Cortico-striatal synaptic defects and OCD-like behaviours in Sapap3-mutant mice. Nature 448:894900.

Witherow DS, Slepak VZ (2003) A novel kind of G protein heterodimer: the G $\beta$ 5-RGS complex. Recept Channels 9:205-212.

Wöhr M, Scattoni ML (2013) Behavioural methods used in rodent models of autism spectrum disorders: current standards and new developments. Behav Brain Res 251:5-17.

Wöhr M, Roullet FI, Hung AY, Sheng M, Crawley JN (2011) Communication impairments in mice lacking Shank1: reduced levels of ultrasonic vocalizations and scent marking behavior. PLoS One 6:e20631.

Yoshii A, Zhao JP, Pandian S, Zundert B, Constantine-Paton M (2013) A myosin Va mutant mouse with disruptions in glutamate synaptic development and mature plasticity in visual cortex. $J$ Neurosci 33:8472-8482.

Yoshimura A, Fujii R, Watanabe Y, Okabe S, Fukui K, Takumi T (2006) Myosin-Va facilitates the accumulation of mRNA/protein complex in dendritic spines. Curr Biol 16:2345-2351.

Yu J, He X, Yao D, Li Z, Li H, Zhao Z (2011) A sex-specific association of common variants of neuroligin genes (NLGN3 and NLGN4X) with autism spectrum disorders in a Chinese Han cohort. Behav Brain Funct 7:13.

Zhang JH, Lai Z, Simonds WF (2000) Differential expression of the G protein beta(5) gene. J Neurochem 75:393-403.

Zhang JH, Pandey M, Seigneur EM, Panicker LM, Koo L, Schwartz OM, Chen W, Chen CK, Simonds WF (2011) Knockout of G protein $\beta 5$ impairs brain development and causes multiple neurologic abnormalities in mice. J Neurochem 119:544-554. 